\author{
Marquette University \\ e-Publications@Marquette
}

Electrical and Computer Engineering Faculty Research and Publications

Electrical and Computer Engineering,

Department of

\title{
Hybrid Field Oriented and Direct Torque Control for Sensorless BLDC Motors Used in Aerial Drones
}

\author{
Kellen Carey \\ Marquette University \\ Nathan M. Zimmerman \\ Johnson Controls International \\ Cristinel Ababei \\ Marquette University, cristinel.ababei@marquette.edu
}

Follow this and additional works at: https://epublications.marquette.edu/electric_fac

Part of the Computer Engineering Commons, and the Electrical and Computer Engineering Commons

\section{Recommended Citation}

Carey, Kellen; Zimmerman, Nathan M.; and Ababei, Cristinel, "Hybrid Field Oriented and Direct Torque Control for Sensorless BLDC Motors Used in Aerial Drones" (2019). Electrical and Computer Engineering Faculty Research and Publications. 631.

https://epublications.marquette.edu/electric_fac/631 
Marquette University

e-Publications@Marquette

\section{Electrical and Computer Engineering Faculty Research and Publications/College of Engineering}

This paper is NOT THE PUBLISHED VERSION; but the author's final, peer-reviewed manuscript. The published version may be accessed by following the link in the citation below.

IET Power Electronics, Vol. 12, No. 3 (March 07, 2019): 438-449. DOI. This article is (C) IEEE and permission has been granted for this version to appear in e-Publications@Marquette. IEEE does not grant permission for this article to be further copied/distributed or hosted elsewhere without the express permission from IEEE.

\section{Hybrid Field Oriented and Direct Torque Control for Sensorless BLDC Motors Used in Aerial Drones}

Kellen D. Carey

Marquette University, Milwaukee, WI

Nathan Zimmerman

Johnson Controls International

Cristinel Ababei

Marquette University, Milwaukee, WI

\footnotetext{
Abstract:

In this study, a sensorless hybrid control scheme for brushless direct current (BLDC) motors for use in multirotor aerial vehicles is introduced. In such applications, the control scheme must satisfy high-performance demands for a wide range of rotor speeds and must be robust to motor parameter uncertainties and measurement noise. The proposed controller combines field-oriented control (FOC) and direct torque control (DTC) techniques to take benefit of the advantages offered by each of these techniques individually. Simulation results demonstrate
} 
the effectiveness of the proposed control scheme over a wide range of rotor speeds as well as good robustness against parameter uncertainties within -5 to $+10 \%$ for inductance and -5 to $+5 \%$ for resistance parameters. The proposed hybrid controller is robust also against noise in voltage and current measurements. In order to verify the results from simulation, the proposed hybrid controller is implemented in hardware using the TI C2000 Piccolo Launchpad and TI BOOSTXL-DRV8305EVM BoosterPack. Testing is done with a Bull Running motor typically used in aerial drones. Testing experiments demonstrate that the hybrid controller reduces the rotor speed ripple when compared to DTC while operating in steady-state mode and decreases the response time to desired speed changes when compared to FOC.

\section{SECTION 1 Introduction}

Sensorless brushless direct current (BLDC) motors are very popular in multirotor aerial vehicles such as quadcopters or drones. While there has been significant work done on the topic of control for BLDC motors used in traditional industrial and electronics applications, much less has been published on the same topic targeting multirotor aerial drones. Nevertheless, much of the control approaches for aerial drones are direct adaptations of the more traditional control solutions despite that aerial drones are more challenging. First, the range of supported rotational speeds is usually much wider to address all operational states, from resting to hovering to complex acrobatics performed in the air. Second, the response time of the control scheme must be very short to be able to effectively support complex manoeuvres and precise control of the flying drones. In addition, power consumption which is directly affected by the quality of the control scheme is important especially in drones, which currently are exclusively powered from batteries.

Despite the large amount of work on control schemes for sensorless BLDC motors in traditional application domains, it is not clear yet what is the best or most appropriate control scheme when it comes to multirotor aerial drones. Most of the previously studied control schemes trade one or more of the performance metrics discussed earlier for the others. That is why, this paper proposes to combine some of the best previously studied control techniques and rotor position estimation techniques and investigates the performance when applied to the case of sensorless BLDC motors used in multirotor aerial vehicles. Preliminary results of this study were discussed in [1]. To this end, the main contributions of this paper include:

- A hybrid controller for BLDC motors that combines the field-oriented control (FOC) and direct torque control (DTC) techniques to take benefit of the advantages offered by each of these techniques individually is proposed.

- The derivation of the state-space equations that represent the electrical-mechanical model of the BLDC motor is presented.

- The state-space model is used in simulations to investigate the performance of the proposed hybrid controller.

- The proposed hybrid controller is further verified with a hardware prototype to confirm results from simulations.

The remainder of this paper is organised as follows. In Section 2, related work is reviewed. In Section 3, the derivation of the motor model that is employed in simulations is presented and the FOC and DTC techniques are discussed. Then, the proposed hybrid control technique is presented in Section 4. In Section 5, simulation results are presented, followed by hardware experiments in Section 6. Finally, the main contributions of this paper are summarised in Section 7. 


\section{SECTION 2 Related work}

Previous work on control of sensorless BLDC motors can be looked at from two perspectives: what actual control method is utilised and what estimation technique is used to calculate the rotor position, which is crucial to the mechanics of any control technique. Representative studies of the most popular control approaches are listed in Table 1. This table presents a comparison of these control schemes in terms of the input variables that are utilised, intermediate variables, actual control technique, supported operation modes, and modelled load characteristics. 
Table 1 Representative control schemes for BLDC motors

\begin{tabular}{|c|c|c|c|c|c|}
\hline Study & Name of approach & Model of motor & Input variables & $\begin{array}{l}\text { Intermediate states for control } \\
\text { technique }\end{array}$ & Load characteristics \\
\hline$[2]$ & $\begin{array}{l}\text { FEM info assisted state } \\
\text { observer }\end{array}$ & mechanical & $I_{a}, I_{b}, V_{a}, V_{b}$ & line-to-line flux linkage & constant load torque \\
\hline [3] & I-F starting method & mechanical & $I_{a}, I_{b}, V_{a}, V_{b}$ & $\theta, \omega$ & $\begin{array}{l}\text { mechanical torque depends } \\
\text { on motor speed }\end{array}$ \\
\hline [4] & $\begin{array}{l}\text { speed-independent } \\
\text { position function }\end{array}$ & electrical & $I_{a}, I_{b}, V_{a}, V_{b}$ & $\begin{array}{l}\text { no explicit } \theta \text {, generate functions } \\
\text { of it }\end{array}$ & not modelled \\
\hline$[5]$ & unknown state observer & electrical & $I_{a b}, I_{b c}, I_{c a}, V_{a b}, V_{b c}, V_{c a}$ & $E_{a b}, E_{b c}, E_{c a}$ & $\begin{array}{l}\text { not modelled, experiments } \\
\text { for variable torque }\end{array}$ \\
\hline$[6]$ & current injection & electrical & $I_{a+}, I_{a-}, I_{b+}, I_{b-}, I_{c+}, I_{c-}$ & $\Delta I_{a}, \Delta I_{b}, \Delta I_{c}, \Delta \Delta I_{a}, \Delta \Delta I_{b}, \Delta \Delta I_{c}$ & not modelled \\
\hline [7] & iterative learning & mechanical & $I_{a}, I_{b}, V_{a}, V_{b}$ & several & constant mechanical torque \\
\hline$[8]$ & field-oriented control & electrical & $I_{a}, I_{b}, V_{a}, V_{b}, V_{c}$ & $I_{d}, I_{q}, \theta, \omega$ & not modelled \\
\hline [9] & direct torque control & electrical & $I_{a}, I_{b}, V_{a}, V_{b}$ & $\psi, T_{e}, \theta, \omega$ & not modelled \\
\hline
\end{tabular}


The study in [2] presented a control approach, including an algorithm for the transition between open-loop startup and closed-loop control. However, it relies on finite-element analysis of a motor in order to operate. This can be difficult to perform for the variety of motors available for multirotor aerial vehicles. The I-F starting method proposed in [3] focuses mainly on the transition between open-loop and closed-loop control. The speed-independent position function [4] provides information about commutation points by taking a ratio of the back electromotive force (back-EMF) and determining when that ratio exceeds a set threshold. It also claims that the approach can be used as a position function, but this is highly susceptible to noise. The unknown state observer [5] starts with the speed-independent position function as an input into an observer which generates estimates of the back-EMF magnitudes. These are then analysed to determine the position and speed of the rotor. The current injection technique [6] employs high-frequency carrier currents which can be analysed to determine the rotor position due to changes in rotor inductance. A drawback of this approach is the increased power consumption due to the fluctuating currents. The iterative learning approach [7] attempts to determine how much lag is present in the control system in order to correct for the phase delay. FOC and DTC techniques $[8,9]$ have been adapted from induction motors to brushless DC (BLDC) motors and allow for direct control of the motor torque. Their drawbacks are their requirements for knowledge of position and rotor speed.

The vast majority of control techniques found in the literature were proposed for classic BLDC motors that are larger, of higher power ratings, and usually operated at lower rotor speeds than the smaller motors used in aerial drones that operate at higher rotor speeds. While classic BLDC motors are outside the scope of this paper, the reader is referred to recent studies that discuss well these classic approaches [10-12]. In contrast, previous literature on BLDC motor control techniques for aerial applications is less, and it is more common to find studies that focus on flight controllers and path planning for aerial vehicles [13] as well as on manipulation [14]. Nevertheless, one can find previous studies that focus on the actual motor control. For example, the study in [15] proposed a fractional-order (also known as non-integer) proportional-integral-derivative controller that was shown to perform better than the so-called coefficient diagram method. A low-complexity adaptive bias and adaptive gain algorithm for closed-loop electronic speed control was presented in [16]. Many industry white papers and application notes discuss back-EMF FOC techniques to control multi-phase motors, but usually they lack specific details [17-19].

An important aspect of previous control techniques is that they need an estimation technique for the rotor position. This estimation technique is very important because the quality of the estimation directly impacts the performance of the overall control scheme. The majority of the previous techniques used sliding mode observers (SMOs) because they are robust to noise and parameter uncertainties [20-28]. Reduced order observers have been also used due to their computational efficiency and simpler structure [29]. These studies estimate some form of back-EMF either in the stator reference frame or line-to-line values. The back-EMF is directly related to the speed of the motor, so, knowing the value of back-EMF allows to calculate the speed of the motor. Regardless of the back-EMF representation, the estimated values are used to determine the rotor position through the arctangent function. Rotor speed can then be determined from a history of rotor positions. Sliding mode and reduced order observers are not new concepts, and so, most of these studies report various improvements over prior techniques. The study in [20] performed tests of the robustness of the SMO by varying the estimates of rotor resistance and inductance and observing the resulting stability of the system. The study in [21] improves the accuracy of the SMO over a larger speed range by varying the observer gain with estimated velocity. The work in [23] adds feed-forward input in order to reduce estimation delay. In order to reduce the inherent chattering in SMOs, the study in [24] swaps a sign function for a sigmoid function. The reduced order observer in [29] improves the convergence of the error and robustness of the proportional-integral (PI) controller by using reference voltages instead of measured voltages for the inverter, which also reduces the need for filtering. 
A popular approach for rotor position estimation and control is based on back-EMF zero crossing detection $[30,31]$. This approach relies on sensing the points when the back-EMF induced in the motor windings cross zero. The sensing of the phase zero crossing points is done while each of the three phase windings is not powered. Then, information on the zero crossing points is used to control, via PI controllers and pulse width modulation (PWM), the commutation of phase voltages. The zero crossing detection also has the limitation that the back-EMF is zero when the rotor is standstill, very small and with a large signal-to-noise ratio at low speeds that makes the crossing point detection challenging.

\section{SECTION 3 Derivation of the three-phase motor model}

This section presents the derivation of the motor model used to develop the proposed controller as a hybrid combination of the FOC and DTC techniques. A three-phase motor has three windings connected to a neutral point, which is not directly accessible. The electrical equivalent circuit of such a three-phase motor, together with the three-phase inverter to drive it, is shown in Fig. 1. The simplest way to make such a motor to rotate is through a periodic six-step commutation process. This process involves stepping through a six-step sequence in which the three-phase inverter is controlled such that its switches are turned on and off in a pre-determined order. For example, the six steps to control the switches from Fig. 1 are: $(1,4)$ on, $(1,6)$ on, $(3,6)$ on, $(3,2)$ on, $(5,2)$ on, $(5,4)$ on, and then $(1,4)$ on again and so on. In each of these steps, exactly one high-side switch and one lowside switch is turned on at a time. This produces a current through the motor such that a magnetic field is created that helps to turn the rotor.

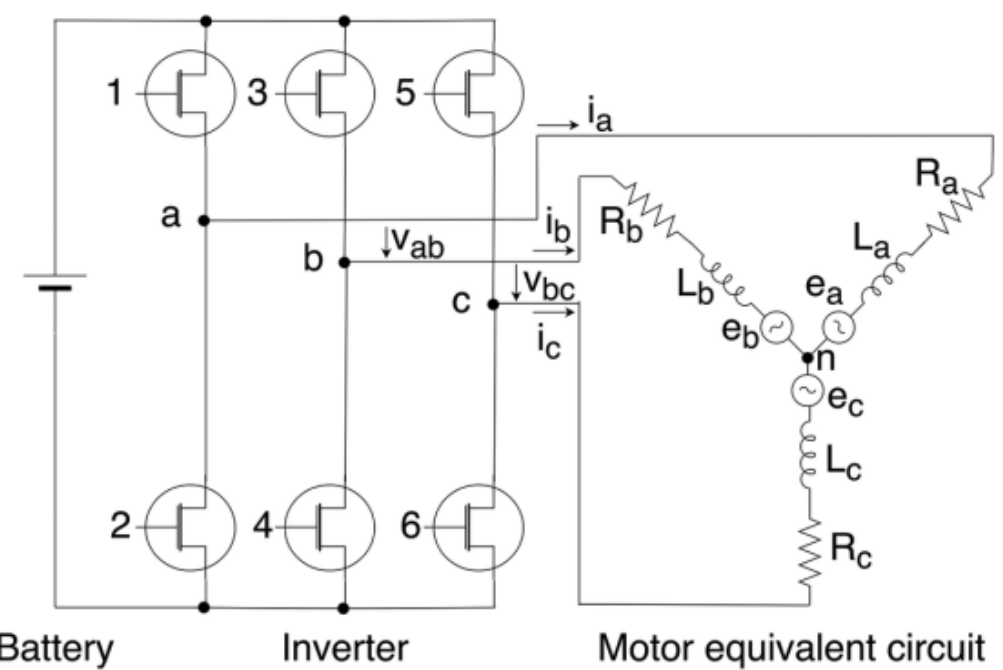

Fig. 1 Equivalent circuit diagram of the inverter and the three-phase motor

Based on the equivalent circuit from Fig. 1, the following equations can be derived:

$$
\begin{aligned}
v_{a n} & =i_{a} R_{a}+L_{a} \frac{\mathrm{d}}{\mathrm{d} t} i_{a}+e_{a} \\
v_{b n} & =i_{b} R_{b}+L_{b} \frac{\mathrm{d}}{\mathrm{d} t} i_{b}+e_{b} \\
v_{c n} & =i_{c} R_{c}+L_{c} \frac{\mathrm{d}}{\mathrm{d} t} i_{c}+e_{c}
\end{aligned}
$$

(1) 
where $R_{x}$ is the phase resistance of phase $x$ (i.e. $a, b$, or $c$ ), $L_{x}$ is the phase inductance, $v_{x n}$ is the instantaneous voltage between phase $x$ and the motor neutral winding point $n, i_{x}$ is the phase current, and $e_{x}$ is the induced back-EMF. The back-EMF is dependent on the rotor position and velocity and is given by the following expression [22]:

$$
\begin{gathered}
e_{a}=k_{e} \omega_{e} f\left(\theta_{e}\right) \\
e_{b}=k_{e} \omega_{e} f\left(\theta_{e}-\frac{2 \pi}{3}\right) \\
e_{c}=k_{e} \omega_{e} f\left(\theta_{e}-\frac{4 \pi}{3}\right)
\end{gathered}
$$

(2)

where $k_{e}$ is the back-EMF constant that is dependent on motor construction, $\omega_{e}$ is the angular velocity of the motor, $\theta_{e}$ is the electrical rotor position, and $f\left(\theta_{e}\right)$ is a trapezoidal function. Rearranging the expressions from $(\underline{1})$, the following set of equations can be derived:

$$
\begin{aligned}
\frac{\mathrm{d}}{\mathrm{d} t} i_{a} & =\frac{1}{L_{a}} v_{a n}-\frac{R_{a}}{L_{a}} i_{a}-\frac{1}{L_{a}} e_{a} \\
\frac{\mathrm{d}}{\mathrm{d} t} i_{b} & =\frac{1}{L_{b}} v_{b n}-\frac{R_{b}}{L_{b}} i_{b}-\frac{1}{L_{b}} e_{b} \\
\frac{\mathrm{d}}{\mathrm{d} t} i_{c} & =\frac{1}{L_{c}} v_{c n}-\frac{R_{c}}{L_{c}} i_{c}-\frac{1}{L_{c}} e_{c}
\end{aligned}
$$

(3)

As the neutral point of the motor windings is not directly accessible for measurement, an alternate must be derived. Hence, using $v_{a b}=v_{a n}-v_{b n}, v_{b c}=v_{b n}-v_{c n}$ and assuming that in a balanced or symmetrical motor we have $L_{a}=L_{b}=L_{c}=L$ and $R_{a}=R_{b}=R_{c}=R$, the differences between the above equations can be calculated in order to eliminate the neutral voltage measurement. This results in the following equations:

$$
\begin{aligned}
& \frac{\mathrm{d}}{\mathrm{d} t}\left(i_{a}-i_{b}\right)=\frac{1}{L} v_{a b}-\frac{R}{L}\left(i_{a}-i_{b}\right)-\frac{1}{L} e_{a b} \\
& \frac{\mathrm{d}}{\mathrm{d} t}\left(i_{b}-i_{c}\right)=\frac{1}{L} v_{b c}-\frac{R}{L}\left(i_{b}-i_{c}\right)-\frac{1}{L} e_{b c}
\end{aligned}
$$

(4)

where $e_{a b}=e_{a}-e_{b}$ and $e_{b c}=e_{b}-e_{c}$. Additionally, since $i_{a}+i_{b}+i_{c}=0$, we can substitute $i_{c}=-\left(i_{a}+\right.$ $i_{b}$ ) into (4) and solve for $\mathrm{d} i_{a} / \mathrm{d} t$ and $\mathrm{d} i_{b} / \mathrm{d} t$. In this way, the following equations, which represent the electrical portion of the model used in this paper, are derived:

$$
\frac{\mathrm{d}}{\mathrm{d} t}\left[\begin{array}{l}
i_{a} \\
i_{b}
\end{array}\right]=\left[\begin{array}{cc}
-\frac{R}{L} & 0 \\
0 & -\frac{R}{L}
\end{array}\right]\left[\begin{array}{l}
i_{a} \\
i_{b}
\end{array}\right]+\left[\begin{array}{cc}
\frac{2}{3 L} & \frac{1}{3 L} \\
-\frac{1}{3 L} & \frac{1}{3 L}
\end{array}\right]\left[\begin{array}{l}
v_{a b}-e_{a b} \\
v_{b c}-e_{b c}
\end{array}\right]
$$

(5) 
On the other hand, the Newton's second law of motion applied to the dynamics of rotating masses gives the following relationship between torque and acceleration [32]:

$$
\frac{\mathrm{d} \omega_{m}}{\mathrm{~d} t}=\frac{1}{J} \Sigma T
$$

(6)

where $\Sigma T$ is the sum of the torques, $J$ is the rotational moment of inertia of the rotor, $\omega_{m}$ is the mechanical angular velocity of the motor, and $\mathrm{d} \omega / \mathrm{d} t$ is the mechanical angular acceleration since acceleration is the derivative of velocity.

The torques present in a motor include the electromagnetic (or developed) torque, the load torque, and the mechanical drag. The developed electromagnetic torque is denoted as $T_{e}$ and the load torque as $T_{l}$. The mechanical drag depends on the rotor speed and is typically given by the expression $\beta \omega_{m}$. In this expression, $\beta$ is a constant that depends on the motor construction and once again $\omega_{m}$ is the rotor mechanical angular velocity. Substituting in $\omega_{m}=(2 / p) \omega_{e}$, the following equation relating angular velocity and torque is arrived at [33]

$$
\frac{\mathrm{d} \omega_{m}}{\mathrm{~d} t}=\frac{1}{J}\left(T_{e}-T_{l}-\frac{2 \beta}{p} \omega_{e}\right)
$$

(7)

The developed electromagnetic torque is given by the following expression [5]:

$$
T_{e}=k_{t}\left[i_{a} f\left(\theta_{e}\right)+i_{b} f\left(\theta_{e}-\frac{2 \pi}{3}\right)+i_{c} f\left(\theta_{e}-\frac{4 \pi}{3}\right)\right]
$$

(8)

where $k_{t}$ is the torque constant for the motor which depends on motor construction and $\theta_{e}$ is the electrical angle of the rotor or rotor position.

Using ( $\underline{5})$ and $(\underline{6})$, together with the fact that $(\mathrm{d} / \mathrm{d} t) \theta_{e}=\omega_{e}$, the following state-space equations to represent the electrical-mechanical model of the three-phase BLDC motor can be derived: 


$$
\begin{aligned}
\frac{\mathrm{d}}{\mathrm{d} t}\left[\begin{array}{c}
i_{a} \\
i_{b} \\
\omega_{e} \\
\theta_{e}
\end{array}\right] & =\left[\begin{array}{cccc}
-\frac{R}{L} & 0 & 0 & 0 \\
0 & -\frac{R}{L} & 0 & 0 \\
0 & 0 & -\frac{p \beta}{2 J} & 0 \\
0 & 0 & 1 & 0
\end{array}\right]\left[\begin{array}{c}
i_{a} \\
i_{b} \\
\omega_{e} \\
\theta_{e}
\end{array}\right] \\
& +\left[\begin{array}{ccc}
\frac{2}{3 L} & \frac{1}{3 L} & 0 \\
-\frac{1}{3 L} & \frac{1}{3 L} & 0 \\
0 & 0 & \frac{p}{2 J} \\
0 & 0 & 0
\end{array}\right]\left[\begin{array}{c}
v_{a b}-e_{a b} \\
v_{b c}-e_{b c} \\
T_{e}-T_{l}
\end{array}\right]
\end{aligned}
$$

(9)

This system of equations, along with (ㅁ) and (ㄹ) $)$ represents the model that will be used to simulate the operation of the proposed control for a three-phase BLDC motor.

\section{SECTION 4 Proposed hybrid controller}

\subsection{System-level block diagram}

This section describes the system-level diagram of the proposed hybrid control scheme for BLDC motors and present details about each of the specific control techniques employed. The system-level diagram is shown in Fig. 2. The idea is to combine the FOC and DTC control techniques in a way that takes benefit of the advantages of each technique in order to reduce the response time and the steady-state error. The benefits of the DTC technique are its lower computational cost and faster responses to changes in load torque or desired speed when compared with the FOC technique. In contrast, the benefits of the FOC technique include lower speed ripple and power consumption at steady-state operation compared to DTC.

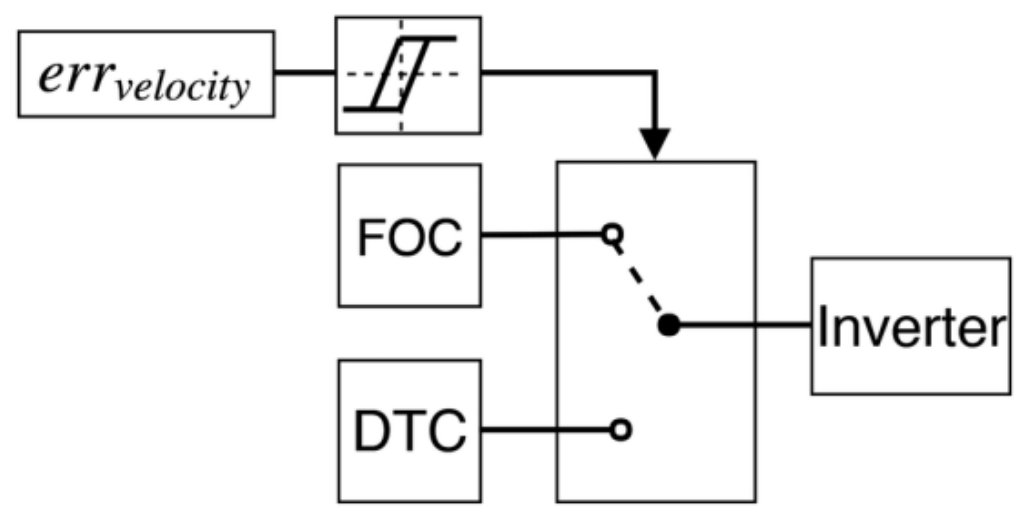

Fig. 2 System-level block diagram of the proposed hybrid controller

As the FOC technique performs better during steady-state operation and the DTC technique performs better during transient operation, the hybrid controller implements a scheme to select between the two techniques. The error in rotor velocity or speed dictates how this selection is made. That is, the FOC technique is selected if 
the rotor velocity error is less than a pre-determined threshold. Otherwise, if the error is larger than the predetermined threshold, the controller selects the DTC technique. Next, the FOC and DTC control techniques are described.

\subsection{Field-oriented control}

FOC, also known as vector control, was originally designed for AC induction machines, but was adapted for DC machines as a means of reducing torque ripple and noise [34]. The idea of FOC is to represent torque and flux as two distinct and separately controllable variables. As the maximum torque is developed when the rotor magnetic field lags the stator generated magnetic field by 90 electrical degrees, FOC attempts to maintain a constant 90 electrical degree torque angle while also controlling the torque magnitude. Since speed is proportional to the time integral of the net torque, the motor speed can be controlled by controlling the developed torque. Practical implementations of the FOC technique usually follow the sequence of operations illustrated in Fig. 3.

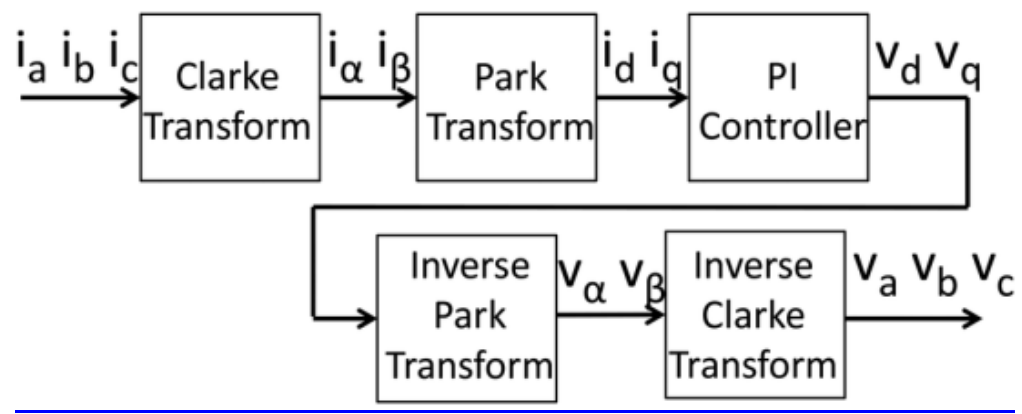

Fig. 3 FOC technique is implemented as a sequence of several operations

To represent the resultant flux and torque as orthogonal values, the three-phase current values are transformed into a stator-stationary two-phase representation by using the Clarke's transformation [35, 36]

$$
\left[\begin{array}{l}
i_{\alpha} \\
i_{\beta}
\end{array}\right]=\frac{2}{3}\left[\begin{array}{ccc}
1 & -\frac{1}{2} & -\frac{1}{2} \\
0 & \frac{\sqrt{3}}{2} & -\frac{\sqrt{3}}{2}
\end{array}\right]\left[\begin{array}{l}
i_{a} \\
i_{b} \\
i_{c}
\end{array}\right]
$$

where $i_{\alpha}$ and $i_{\beta}$ are the phase currents represented in the $(\alpha \beta)$ frame of reference. Furthermore, under the assumption that the motor is a balanced three-phase system, i.e. $i_{a}+i_{b}+i_{c}=0$, ic can be eliminated to derive the simplified Clarke's transformation

$$
\left[\begin{array}{l}
i_{\alpha} \\
i_{\beta}
\end{array}\right]=\left[\begin{array}{ll}
1 & 0 \\
\frac{1}{\sqrt{3}} & \frac{2}{\sqrt{3}}
\end{array}\right]\left[\begin{array}{l}
i_{a} \\
i_{b}
\end{array}\right]
$$

The two-phase $(\alpha \beta)$ representation does not take into account the rotor position. However, knowledge of the rotor position is necessary to ensure that the stator-generated magnetic field is 90 electrical degrees ahead of the rotor magnetic field. Therefore, the $(\alpha \beta)$ system of coordinates is rotated from the stator reference into the rotor reference by $\theta_{e}$, the rotor's electrical position. This is accomplished by using Park's transformation [35, 36] 


$$
\left[\begin{array}{l}
i_{d} \\
i_{q}
\end{array}\right]=\left[\begin{array}{cc}
\cos \left(\theta_{e}\right) & \sin \left(\theta_{e}\right) \\
-\sin \left(\theta_{e}\right) & \cos \left(\theta_{e}\right)
\end{array}\right]\left[\begin{array}{l}
i_{\alpha} \\
i_{\beta}
\end{array}\right]
$$

This transformation together with the Clarke's transformation are geometrically illustrated in Fig. 4. At this point, the two quantities in the $(d q)$ coordinate system represent the torque (aligned with axis $q$ ) and the resultant rotor flux (aligned with axis $d$ ) of the motor. Since these quantities are orthogonal to each other, they can be independently controlled, typically through separate PI controllers, in order to generate the desired $(d q)$ voltages. In order to apply the desired voltages, the $(d q)$ quantities need to be converted back into the $(\alpha \beta)$ frame of reference. This is accomplished by rotating the $(d q)$ quantities by $-\theta_{e}$ as given by Park's inverse transformation $[35,36]$

$$
\left[\begin{array}{l}
v_{\alpha} \\
v_{\beta}
\end{array}\right]=\left[\begin{array}{cc}
\cos \left(\theta_{e}\right) & -\sin \left(\theta_{e}\right) \\
\sin \left(\theta_{e}\right) & \cos \left(\theta_{e}\right)
\end{array}\right]\left[\begin{array}{l}
v_{d} \\
v_{q}
\end{array}\right]
$$

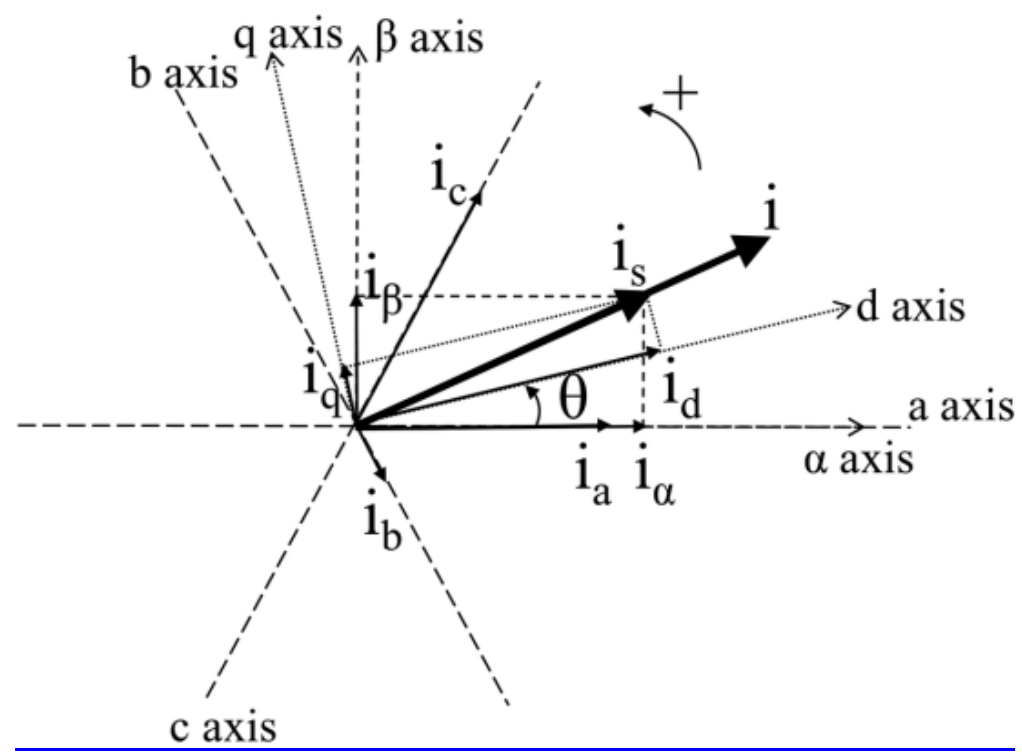

Fig. 4 Projections $(a, b, c) \rightarrow(\alpha, \beta)$ and $(\alpha, \beta) \rightarrow(d, q)$ transform a three-phase time and speed dependent system into a two coordinate, $(d, q)$, time-invariant system

Finally, the $(\alpha \beta)$ components can be used directly by a space-vector modulation (SVM) controller in order to generate the PWM phase quantities that control the inverter connected to the three-phase motor. Or alternatively, they can be converted back into the three-phase $(a b c)$ system through the Clarke's inverse transformation $[35,36]$

$$
\left[\begin{array}{l}
v_{a} \\
v_{b} \\
v_{c}
\end{array}\right]=\left[\begin{array}{cc}
1 & 0 \\
-\frac{1}{2} & \frac{\sqrt{3}}{2} \\
-\frac{1}{2} & -\frac{\sqrt{3}}{2}
\end{array}\right]\left[\begin{array}{l}
v_{\alpha} \\
v_{\beta}
\end{array}\right]
$$




\subsection{Direct torque control}

DTC, also known as direct self-control, was developed in the eighties [37, 38]. Compared to the FOC technique, the DTC technique has the advantage of a simpler control structure and reduced computational complexity. Thus, it offers a faster response to changes in load torque and desired speed. Therefore, the DTC technique is used during transitions between different speeds. A drawback of the DTC technique is that it exhibits increased torque ripple.

The implementation of the DTC technique requires estimates of the generated torque and flux. The stator flux linkage can be represented as orthogonal $\alpha$ and $\beta$ components in the $(\alpha \beta)$ coordinate system. Each of these components can be found by computing the integral [39]

$$
\psi_{x}(t)=\int_{0}^{t}\left(v_{x}-R i_{x}\right) \mathrm{d} t
$$

where $\psi_{x}$ represents the $\alpha$ or $\beta$ component of the stator flux linkage, $v_{x}$ is the $\alpha$ or $\beta$ component of the voltage, and $i_{x}$ is the $\alpha$ or $\beta$ component of the current. Using these values then, the flux linkage magnitude and produced electrical torque can be found using the following expressions [39]:

$$
\begin{aligned}
|\psi(t)| & =\sqrt{\left(\psi_{\alpha}(t)\right)^{2}+\left(\psi_{\beta}(t)\right)^{2}} \\
T_{e}(t) & =\frac{3}{4} p\left(\psi_{\alpha}(t) i_{\beta}+\psi_{\beta}(t) i_{\alpha}\right)
\end{aligned}
$$

(16)

where $\psi(t)$ is the stator flux linkage at time $t$ and $p$ is the number of motor poles.

The actual control of the inverter driving the three-phase motor is implemented through space-vector techniques. This is illustrated in Fig. 5, which shows all six vector combinations of controlling the inverter. Each of the vectors encodes whether the high-side driver is switched on, represented by a ' 1 ', or off, represented by a ' 0 '. The low-side driver is assumed to be in the opposite state of its corresponding high-side driver. As the motor is a three-phase system, there are eight possible states for the inverter, out of which only six are shown in Fig. 5. States 0 and 7 are not included because they correspond to the cases when the high-side drivers are either all off or on. 


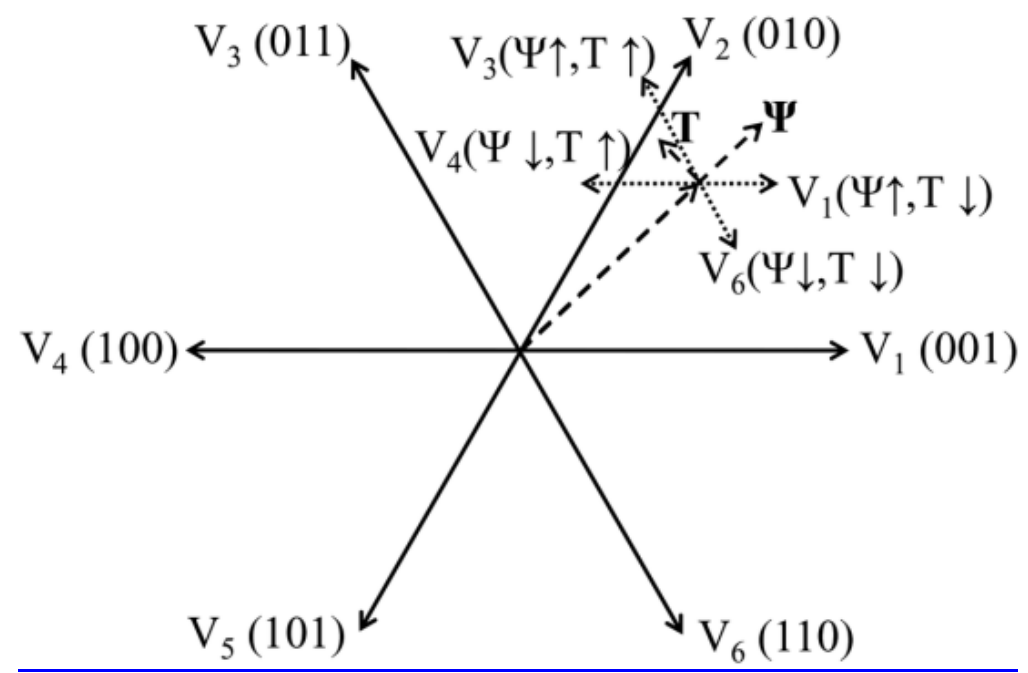

Fig. 5 Illustration of the SVM used to implement the DTC technique

Despite not employing Park's transformations that rely on precise position information, the DTC technique still requires knowledge of the rotor position in order to determine which sector of Fig. 5 the rotor is in and thus to know how to control the inverter. Keeping track of the rotor position can be achieved through a look-up table (LUT) shown in Table 2. This LUT is indexed by the rotor position, flux error $\left(\operatorname{err}_{\psi}\right)$, and torque $\operatorname{error}\left(\operatorname{err}_{\tau}\right)$ to find the correct space vector control signal that needs to be applied to the inverter [40].

Table 2 LUT used by the DTC technique

\begin{tabular}{|l|l|l|l|l|l|l|l|}
\hline $\operatorname{err}_{\psi}$ & $\operatorname{err}_{\tau}$ & $\mathbf{1}$ & $\mathbf{2}$ & $\mathbf{3}$ & $\mathbf{4}$ & $\mathbf{5}$ & $\mathbf{6}$ \\
\hline 1 & 1 & V2 & V3 & V4 & V5 & V6 & V1 \\
\hline 1 & 0 & V7 & V0 & V7 & V0 & V7 & V0 \\
\hline 1 & -1 & V6 & V1 & V2 & V3 & V4 & V5 \\
\hline-1 & 1 & V3 & V4 & V5 & V6 & V1 & V2 \\
\hline-1 & 0 & V0 & V7 & V0 & V7 & V0 & V7 \\
\hline-1 & -1 & V5 & V6 & V1 & V2 & V3 & V4 \\
\hline
\end{tabular}

\subsection{Sliding-mode observer}

The FOC and DTC techniques use rotor position information to generate the correct control signals. The rotor position could be easily calculated if one had direct measurements of the back-EMF signals generated by the motor three phases. However, because the neutral winding of the motor is not accessible, such direct measurements are not directly available in motors used in aerial drones. Therefore, one must rely on estimates of the back-EMF signals, which can be calculated from measurements of the phase-to-phase voltages and phase currents, which do not require access to the neutral point of the windings inside the motor.

The most popular estimation technique of the back-EMF signals is theSMO technique because of its many advantages including good robustness to parameter uncertainty and variation, and low computational complexity, which in turn leads to fast convergence and dynamic response [26, 27]. The SMO technique uses currents and voltages expressed in the $(\alpha \beta)$ frame. A common formulation of the continuous time SMO is given by [23] 


$$
\begin{aligned}
& \frac{\mathrm{d} i_{\alpha}}{\mathrm{d} t}=-\frac{R}{L} \hat{i}_{\alpha}+\frac{1}{L}\left(v_{\alpha}-e_{\alpha}\right)+K_{1} \operatorname{sat}\left(\operatorname{err}_{\alpha}\right) \\
& \frac{\mathrm{d} i_{\beta}}{\mathrm{d} t}=-\frac{R}{L} \hat{i}_{\beta}+\frac{1}{L}\left(v_{\beta}-e_{\beta}\right)+K_{1} \operatorname{sat}\left(\operatorname{err}_{\beta}\right) \\
& \frac{\hat{\mathrm{d}}_{\alpha}}{\mathrm{d} t}=K_{2} \operatorname{sat}\left(\operatorname{err}_{\alpha}\right) \\
& \frac{\mathrm{d} \hat{e}_{\beta}}{\mathrm{d} t}=K_{2} \operatorname{sat}\left(\operatorname{err}_{\beta}\right)
\end{aligned}
$$

where $e_{x}$ represents the back-EMF signal expressed in the $(\alpha \beta)$ frame of reference, $\hat{i}_{x}$ is the estimated current in the $(\alpha \beta)$ frame of reference, $s=e r r_{x}=i_{x}-i_{x}$ is the sliding surface, and sat $(x)$ is the saturation function defined as

$$
\operatorname{sat}(x)=\left\{\begin{array}{l}
-1, x \leq-1 \\
x,-1 \leq x \leq 1 \\
1, x \geq 1
\end{array}\right.
$$

The values of the parameters $K_{1}$ and $K_{2}$ serve as constraints to ensure the stability of the SMO; they must satisfy the following inequalities [20]:

$$
\begin{aligned}
& K_{1}>\frac{1}{L}|e|_{\text {max }} \\
& K_{2}<0
\end{aligned}
$$

Solving the system from (17) is the basis of finding the estimated values of the back-EMF signals, which are then used to compute the rotor position using the following expression [20]:

$$
\hat{\theta}_{e}=\operatorname{atan} 2\left(\begin{array}{l}
\hat{e}_{\beta} \\
\frac{\hat{e_{\alpha}}}{e_{\alpha}}
\end{array}\right)
$$

where $\hat{\theta}_{e}$ is the estimated electrical position and $\hat{e}_{x}$ is the estimated back-EMF signal in the $(\alpha \beta)$ frame of reference. Having the rotor position calculated, the rotor velocity then can be easily found by taking the time derivative. To reduce the noise introduced and compounded by the derivation operation, a low-pass filter is typically employed. 


\section{SECTION 5 Simulation of the proposed hybrid controller}

\subsection{Simulink model}

In the first phase of verification and testing, simulations are conducted to verify the proposed hybrid controller. For this purpose, a Matlab/Simulink testbench is developed whose system-level block diagram is shown in Fig. 6. This testbench has three main components: (i) the model of a three-phase BLDC motor, which essentially is given by (9), (ii) a control block, which is the proposed hybrid control approach discussed in Fig. 2, and (iii) a simulation block that emulates the six-stage inverter that drives the motor. The motor model block receives as inputs the three-phase voltages and the load torque and calculates the phase currents, the rotor position, and the rotor velocity. The voltage and current signals from the motor model are fed as inputs into the controller block, which determines the control signals that should be used to control the speed of the motor. These control or gate signals are passed to the six-stage inverter, which converts them into voltage signals supplied to the motor model block. The next paragraphs discuss and provide more details about each of these three simulation components or blocks.

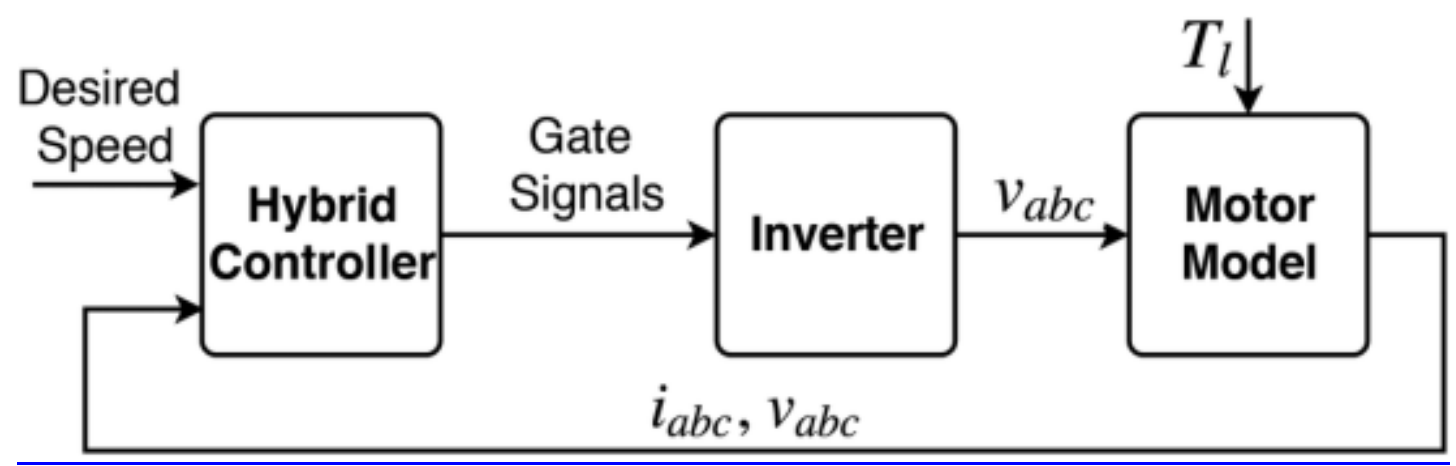

Fig. 6 System-level block diagram of the simulated testbench

The mathematical model for the motor model block is given by $(\underline{9})$ that was derived in Section 3. A simplified diagram of the model block is shown in Fig. 7. Line voltages and the load torque are fed as the inputs into this diagram. The back-EMF voltages are subtracted from the input line voltages to derive $v_{a b}$ and $v_{b c}$, which are then used together with the difference between the generated and load torques, $T_{e}-T_{l}$, as inputs into the state-space equations. The outputs of the simulation of these equations are the motor speed, the rotor position, and the phase currents as shown in Fig. 7. The rotor position and speed are used to compute the back-EMF signal values as expressed by (2). Furthermore, the phase currents and the back-EMF values are combined to determine the electrical torque as dictated by (ㅇ) , which will then be used in the next iteration of the simulation algorithm. 


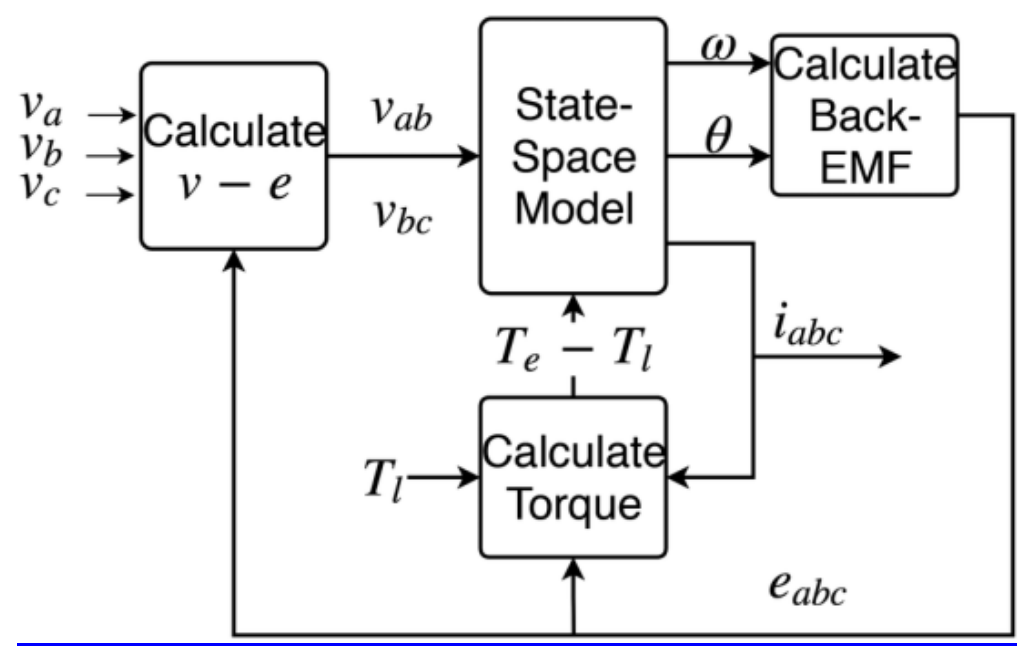

Fig. 7 Diagram of the motor model block from Fig. 6

The controller block from Fig. 6 is detailed in Fig. 8. Here, first, the Clarke's transformation is applied to the voltage and current input values because the FOC, DTC, and SMO techniques require voltages and currents represented in the $(\alpha \beta)$ reference frame. The SMO block from Fig. 8 is further detailed in Fig. 9. The SMO block is responsible with the estimation of the rotor position and speed using (17) and (20). These quantities together with the desired velocity value are used by the FOC and DTC blocks as shown in Fig. 8.

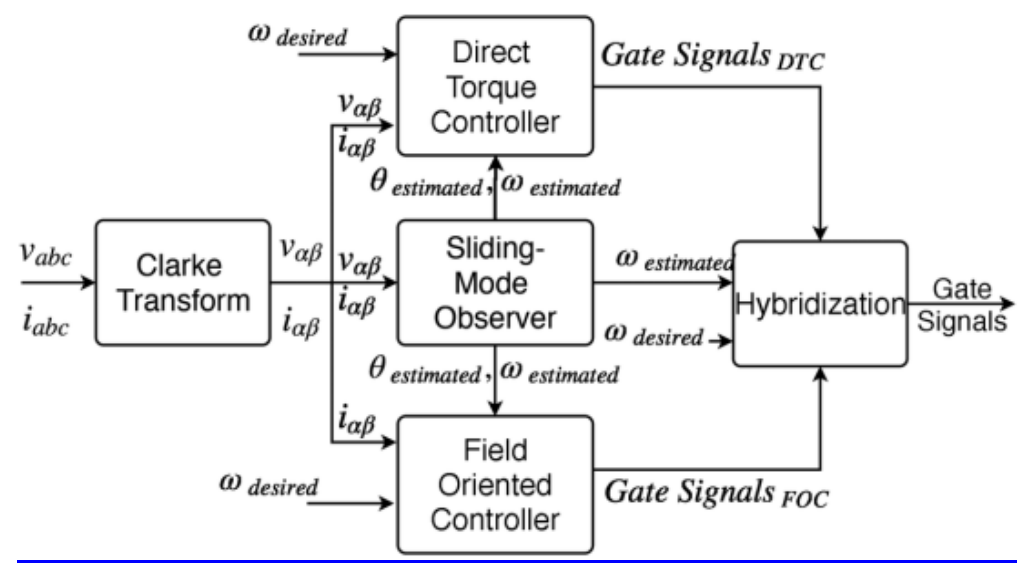

Fig. 8 Diagram of the proposed controller block from Fig. 6

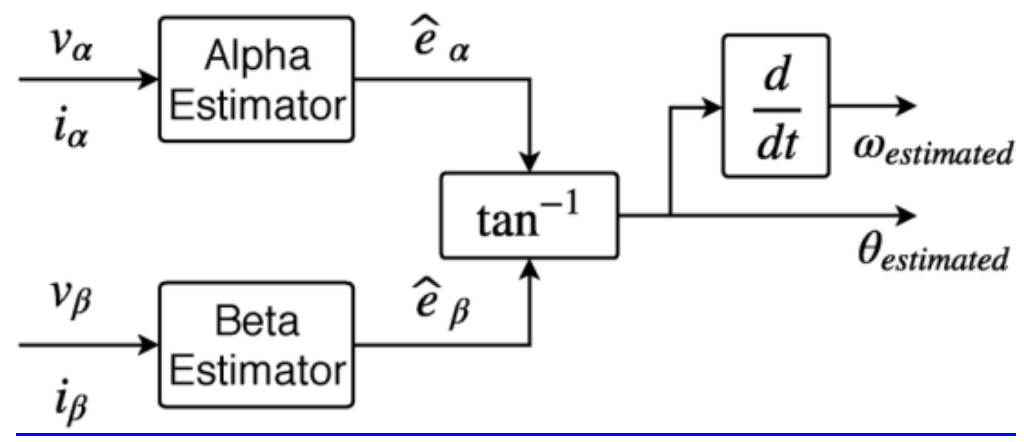

Fig. 9 Details of the SMO block from Fig. 8

Detailed views of the FOC and DTC blocks are shown in Figs. 10 and 11. The FOC block from Fig. 10 receives voltages and currents in the $(\alpha \beta)$ coordinate system. These are converted into their counterparts in the $(d q)$ 
frame using the estimated position and Park's transformation. PI controllers use the rotor speed to determine the desired torque value, the resultant flux error, and the torque error. The desired resultant flux is set to 0 . The resultant flux error and torque error represent the commanded $(d q)$ voltage levels. These $(d q)$ voltage levels are sent through the Park's inverse transformation in order to get the Extra \left or missing \right) components, which then are fed directly into the space-vector modulator to generate the actual command signals for the inverter.

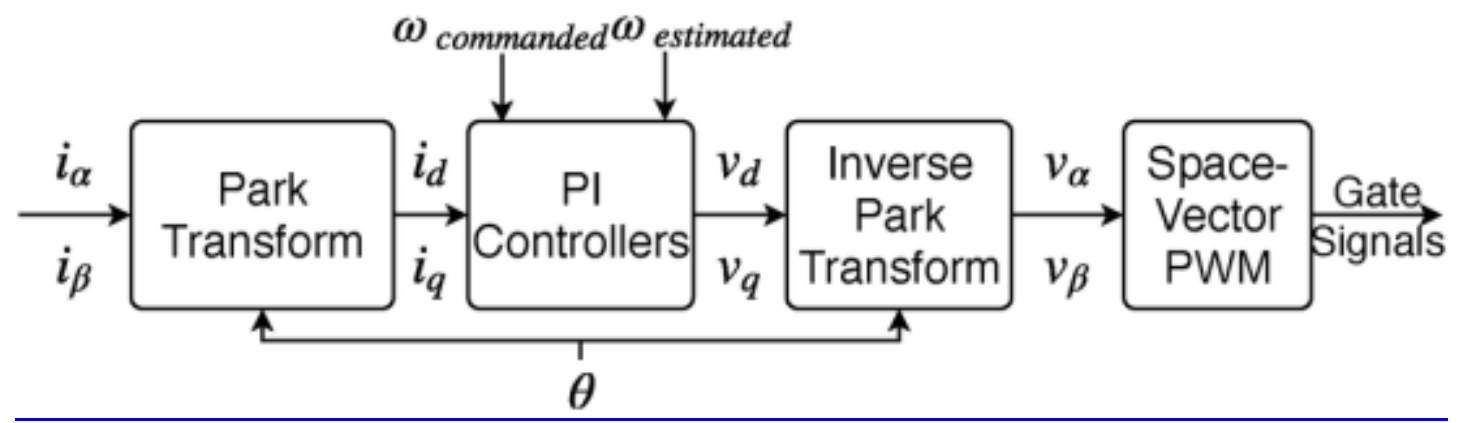

Fig. 10 Details of the FOC block from Fig. 8

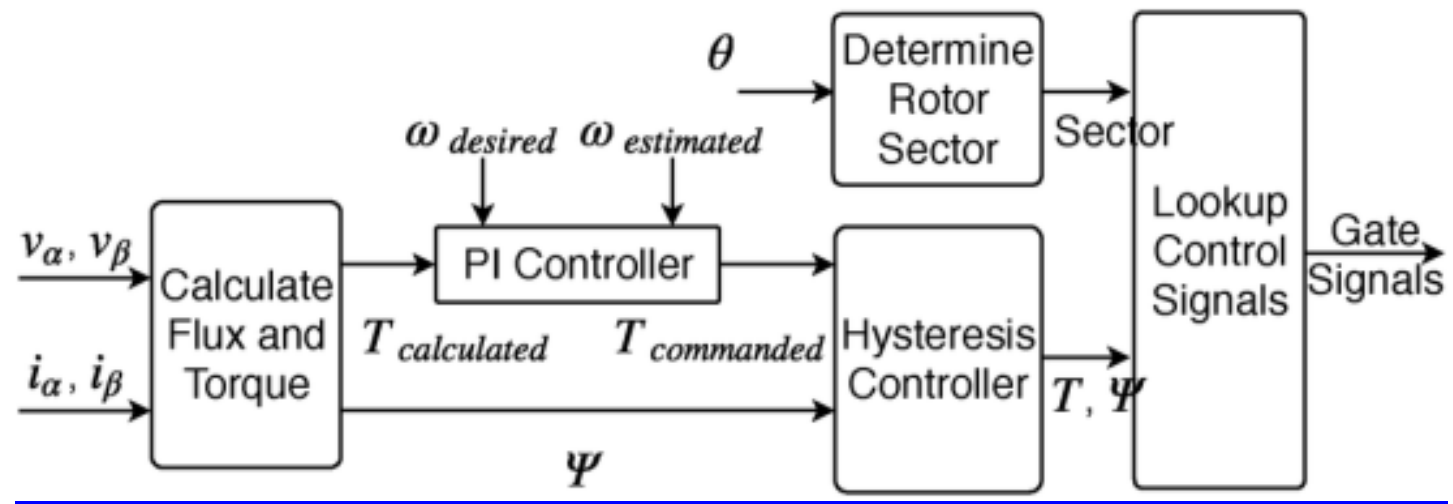

Fig. 11 Details of the DTC block from Fig. 8

The DTC block, detailed in Fig. 11, receives the same voltages and currents in the $(\alpha \beta)$ coordinate system. These are used in (15) and (16) to compute the resultant flux and torque generated by the motor, which are then compared with the desired resultant flux and torque references and sent through hysteresis controllers to determine error signals. The control signals to drive the inverter are generated from the LUT from Table 2, depending on the rotor's sector in the space-vector diagram, the resultant flux, and torque error.

These FOC and DTC blocks generate the control gate signals that are passed to the hybridisation block from Fig. 8, which then generates the final commanded gate signals for the inverter. The implementation details of the hybridisation block are shown in Fig. 12. 


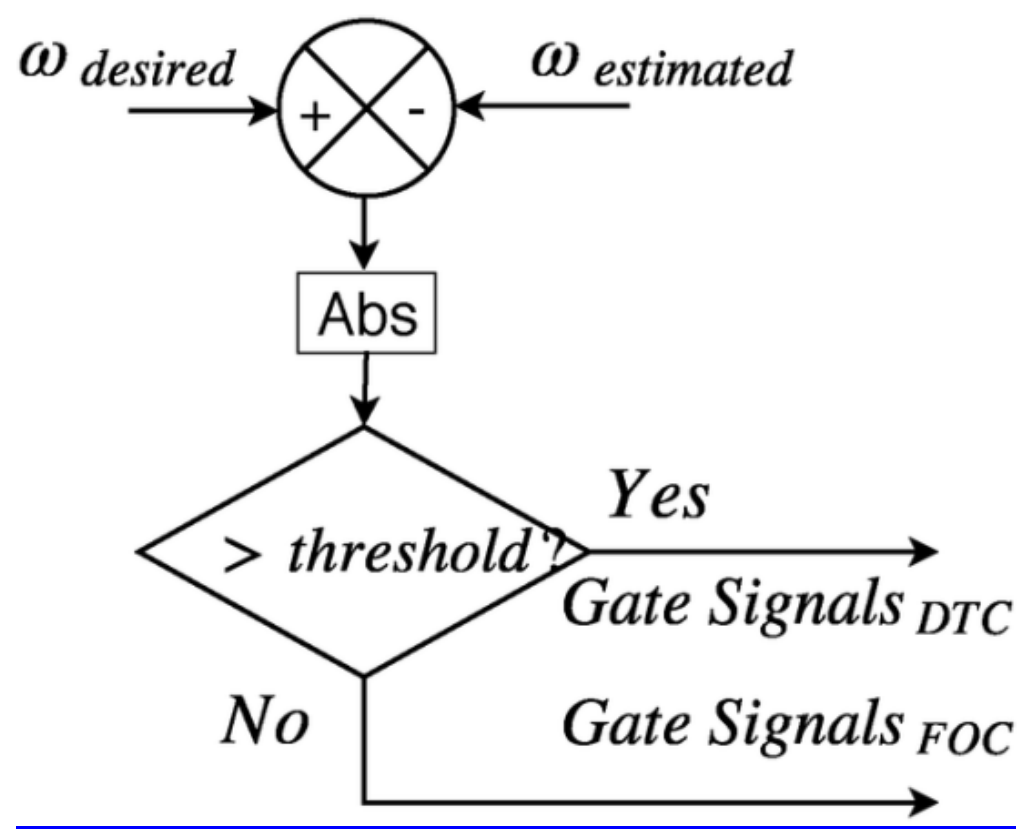

Fig. 12 Details of the hybridisation block from Fig. 8

\subsection{Simulation results}

Now that the details of the simulation setup from Fig. 6 have been discussed, simulation results are reported.

\subsubsection{Motor model}

The motor model used in all simulations is for the Bull Running BR2804-1700 kV BLDC motor, whose picture is shown in Fig. 13. The same motor will be used in the experimental hardware setup later on as well. The parameters of this motor are given in Table 3 . The motor is supplied from a $12 \mathrm{~V}$ power supply.

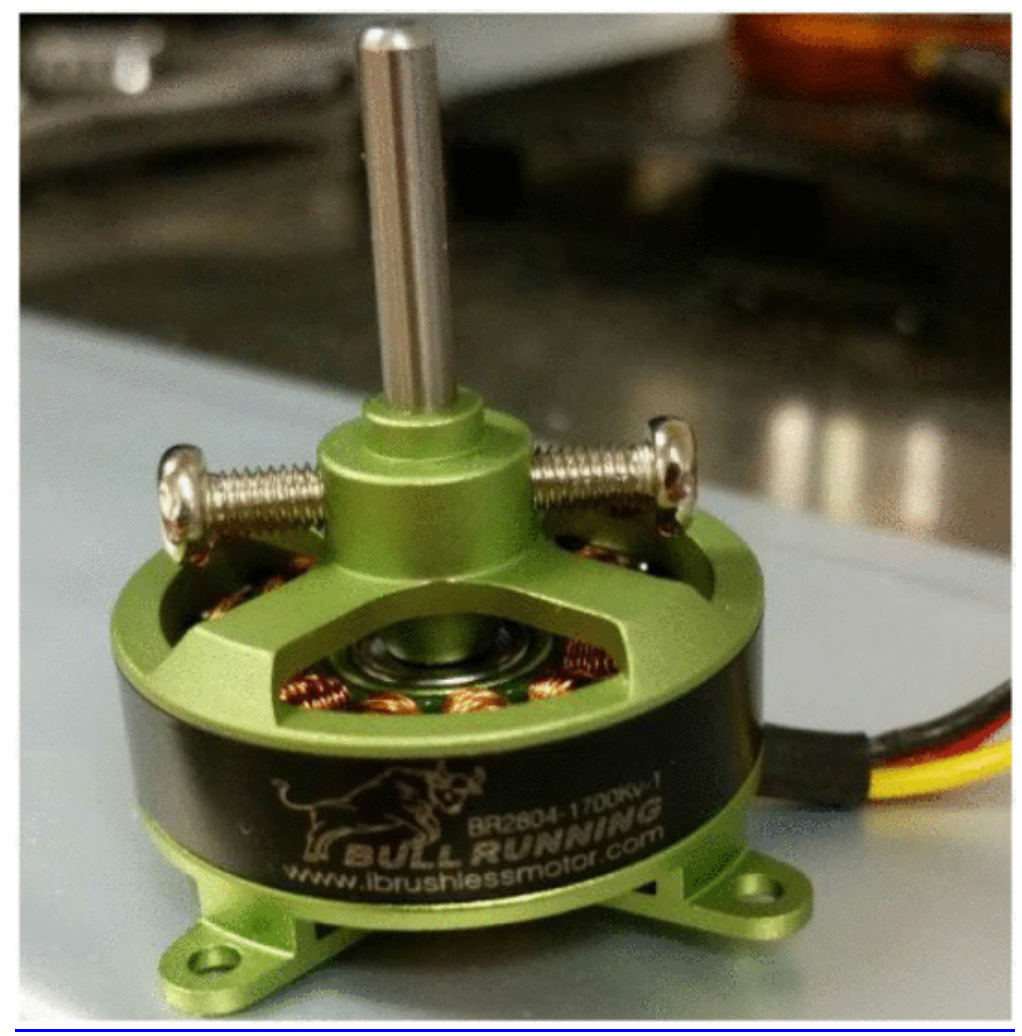


Fig. 13 Picture of the Bull Running motor modelled in our simulations and used in the hardware testing

Table 3 Parameters of the Bull Running motor

\begin{tabular}{|c|l|}
\hline$R$ & $0.11 \Omega$ \\
\hline$L$ & $18 \mu \mathrm{H}$ \\
\hline$J$ & $0.348 \mu \mathrm{N} \times \mathrm{m} / \mathrm{s}^{2}$ \\
\hline$k_{t}$ & $0.54 \mathrm{mN} \times \mathrm{m} / \mathrm{A}$ \\
\hline$k_{e}$ & $0.54 \mathrm{mV} /(\mathrm{rad} / \mathrm{s})$ \\
\hline$k_{f}$ & $0.437 \mu \mathrm{N} \times \mathrm{m} / \mathrm{s}$ \\
\hline$p$ & 14 \\
\hline
\end{tabular}

\subsubsection{Stability analysis and disturbance rejection}

As the proposed hybrid controller is essentially a mechanism to switch between two well-known techniques, the FOC and the DTC techniques, its stability is that of either of the individual technique that is being used at a given time. The same applies for the disturbance rejection characteristics of the proposed controller. These characteristics depend on several parameters, including the actual gains of the PI controllers from Figs. 10 and 11. Moreover, other design attributes are of interest, including the response time to rotor speed change requests and the mean-square rotor speed error during steady-state operation. The response time is given by the time the control takes to reach $95 \%$ of the desired value (for step-up command), starting from when the desired rotor speed changes. The mean-square error (MSE) is given by $(1 / N) \sum_{i=1}^{N}\left(\omega_{\text {desired }}-\right.$ $\left.\omega_{\text {actual }}\right)^{2}$, and is measured when the system is operating in steady state, where $N$ is the number of simulation steps when the rotor is considered to be rotating at a steady speed.

To tune the proposed hybrid controller, a brute-force design space exploration was conducted in order to investigate and identify values for the PI gains, hysteresis band, and the hybridisation threshold (Fig. 12). During this exploration, the following cost function was used in each simulation for a given set of parameter values:

$$
\text { Cost }=\sqrt{(\text { NormRespTime })^{2}+(\text { NormMSE })^{2}}
$$

where the normalised response time NormRespTime is given by Extra close brace or missing open brace and

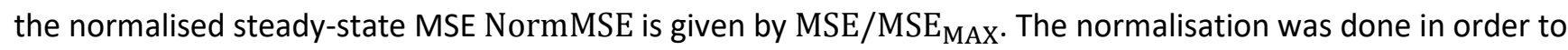
ensure that both cost components counted equally. The best parameters found to minimise the value computed by (21) are listed in Table 4 and are used in all simulations.

Table 4 Controller parameters

\begin{tabular}{|l|l|}
\hline Parameter & Value \\
\hline threshold & 25 (RPM) \\
\hline hysteresis band & 0 (RPM) \\
\hline FOC P Gain & 0.5 \\
\hline FOC I Gain & 0.05 \\
\hline DTC P Gain & 0.35 \\
\hline DTC I Gain & 0.01 \\
\hline
\end{tabular}

Finally, the authors are currently looking into issues related to stability and disturbance rejection during controller switching times between the two individual techniques and will report findings in future work. 


\subsubsection{Speed step-up response}

The first set of simulations compare the speed response of the proposed hybrid controller with the responses of the individual pure FOC and pure DTC techniques, for a speed step-up command. The results of this simulation are presented in Fig. 14. The simulation is run for $2 \mathrm{~s}$ with time being represented on the $x$-axis. The $y$-axis represents the rotor speed. The speed step-up command to change the speed from 500 to 4000 RPM occurs at time $1 \mathrm{~s}$. This command is shown as Reference Speed in the figure, while the three simulated techniques are shown as Pure FOC, Pure DTC, and Hybrid Controller. It is observed that the FOC technique performs rather poorly. It requires a much longer transition time and fails to reach the desired rotor speed. However, the pure FOC technique as well as the hybrid technique have lower steady-state speed ripples compared to the DTC technique. The pure DTC and hybrid techniques have slightly larger ripples at low speed (i.e. 500 RPM), but, they offer a lower mean-square speed error compared to the FOC technique. During transient operation, both the hybrid and the DTC techniques respond quickly, in about $0.1 \mathrm{~s}$. The hybrid approach follows the DTC approach closely, which is expected because the hybridisation block selects the DTC technique to run when the speed error is large. This set of simulations shows that the proposed hybrid technique benefits from the smooth steady-state operation of the FOC technique and the quick transient response of the DTC technique.

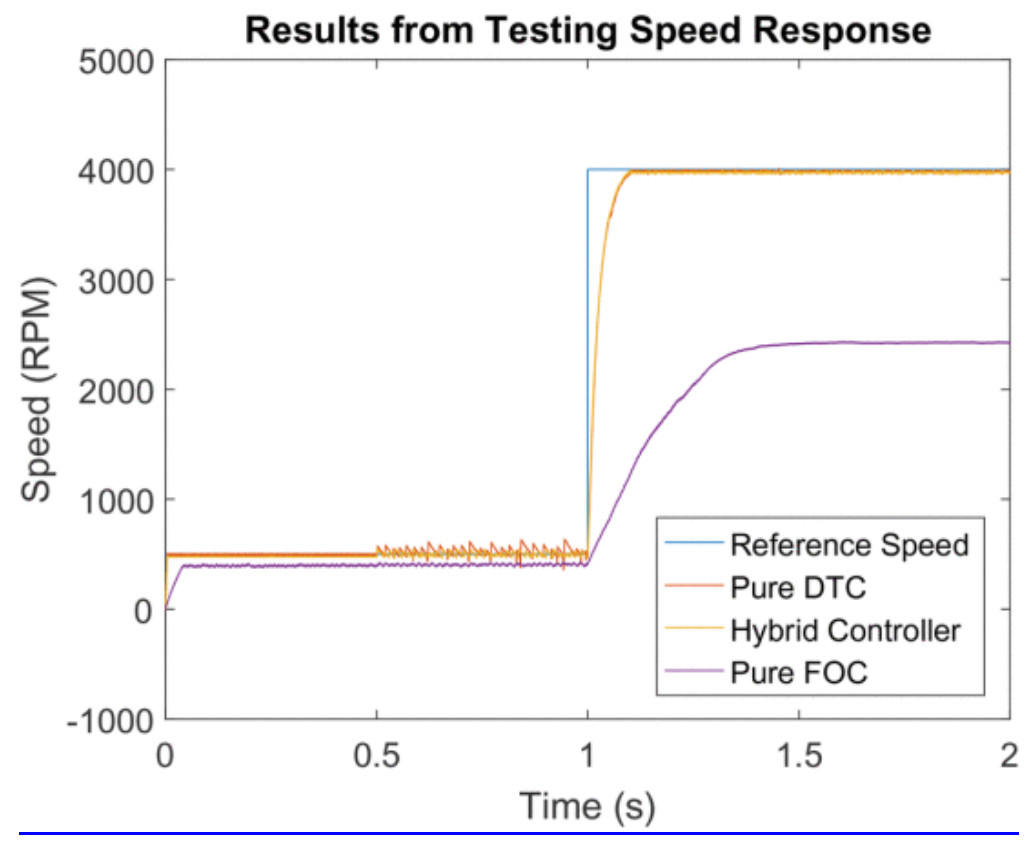

Fig. 14 Comparison of the speed step-up response achieved with the hybrid controller and with the FOC and DTC techniques

\subsubsection{Reference input rotor speed tracking}

This set of simulations look at how the proposed hybrid controller performs for two different rotor speed change requests. First, step changes of the input reference from low to high and from high to low speeds are studied. The simulation results of the step-up and step-down speed responses are shown in Fig. 15. Second, an input reference profile where the desired rotor speed is ramped-up and then ramped-down is investigated. The results are shown in Fig. 16. In both figures, the desired input rotor speed is shown as Reference Speed and the speed achieved by the hybrid controller is shown as Actual Speed. It can be observed that the hybrid controller offered good performance in both cases. The response is fast and the steady-state speed is settled to very quickly in the case of the step responses. Also, the ramp speeds are tracked well. 


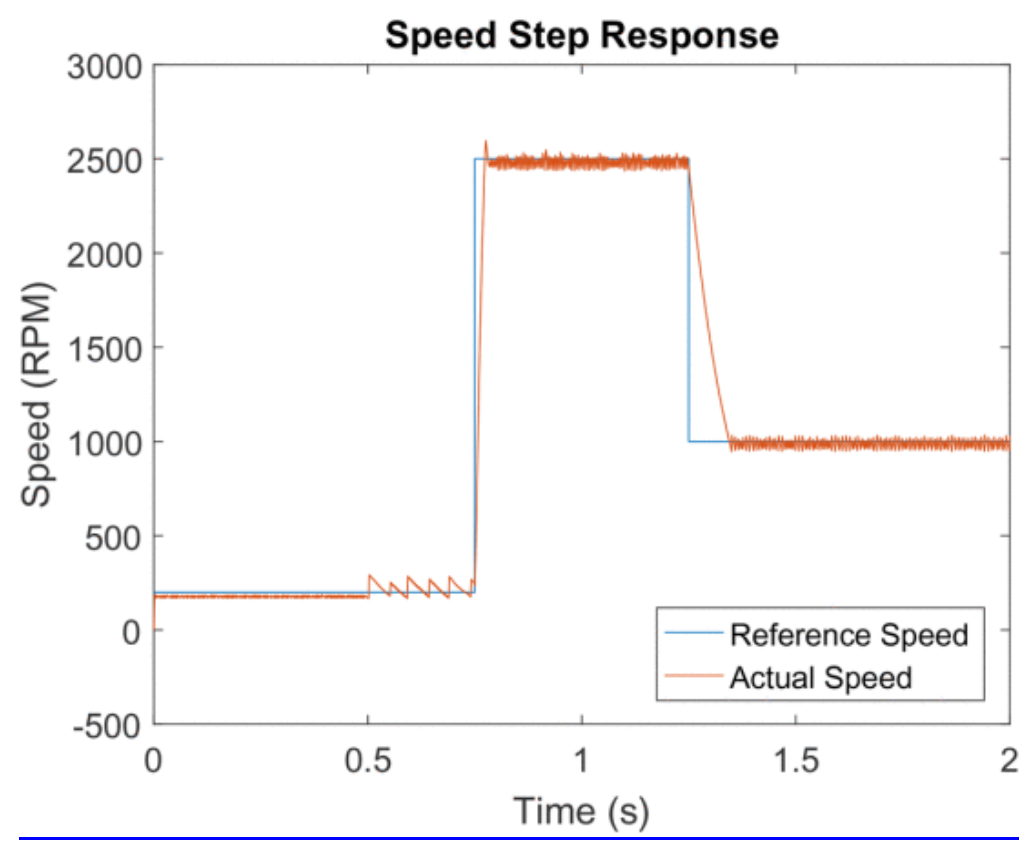

Fig. 15 Speed response to step-up and step-down controls achieved with the proposed hybrid controller

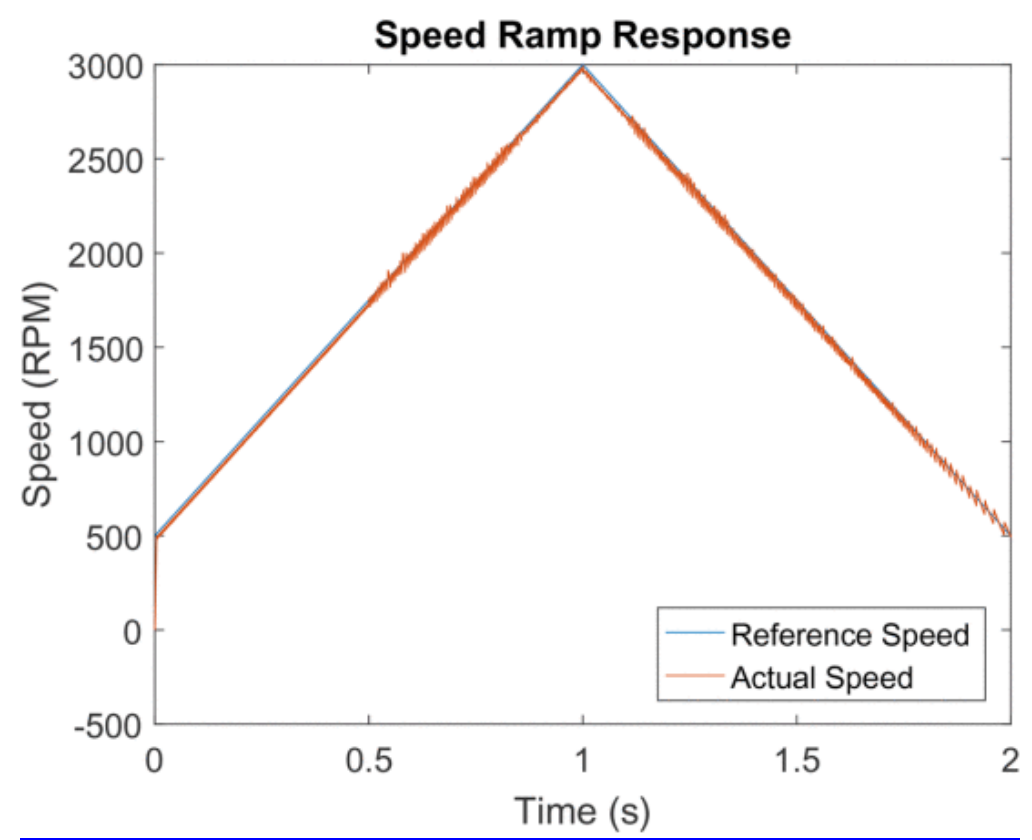

Fig. 16 Speed response to ramp-up and ramp-down controls achieved with the proposed hybrid controller

\subsubsection{Load response}

In the next set of simulations, the objective is to find out the maximum achievable rotor speed with the proposed hybrid controller in two different situations: with and without mechanical loading. To determine the mechanical loading, information from the UIUC propeller database available at [41] is used. The mechanical torque due to the propeller at a given velocity, $\tau$, can be computed with the following expression:

$$
\tau=C_{p} \rho n^{2} D^{5}
$$


where $C_{p}$ is a constant dependent on the propeller design, typically with a value of 0.05 [41], $\rho=$ $1.225 \mathrm{~kg} / \mathrm{m}^{3}$ is the air density, $n$ is the speed of the rotor in radians per second, and $D$ is the diameter of the propeller in metres. In this work, an 8-inch or $0.2032 \mathrm{~m}$ propeller diameter is studied and based on the information available at [41], it is assumed that $C_{p}=0.05$.

Fig. 17 reports the results of these simulations. It can be seen that the proposed control scheme can attain a maximum rotor speed of slightly over 5000 RPM without mechanical loading and almost 4000 RPM with mechanical loading. This is expected because the generated electrical torque (see (요) indicates that the produced torque is dependent on the current through each phase. Thus, only a fixed amount of torque can be produced because only a limited amount of power is available and supplied to the motor.

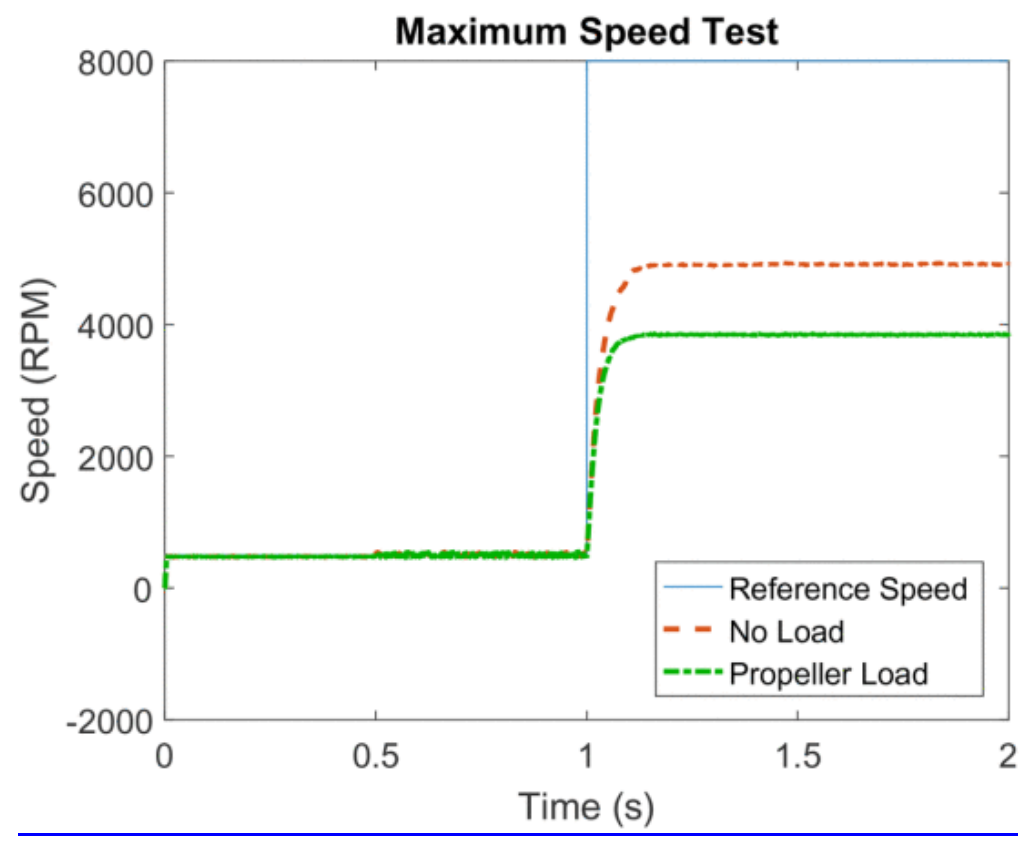

Fig. 17 Simulation results from testing for the maximum attainable rotor speed with and without propellerloaded control

\subsubsection{Noise sensitivity}

This section studies the performance of the hybrid controller when white noise is injected into the simulated system. The noise mimics practical variations or uncertainties in voltage measurements. The objective is to observe how susceptible the proposed hybrid controller is to voltage measurement noise. More specifically, noise is injected artificially in the input voltages, $v_{a b c}$, of the controller from Fig. 8. The voltage noise is injected following a Gaussian distribution with zero mean and with a standard deviation varied in the interval $0 . .2 \mathrm{~V}$ with increments of $0.4 \mathrm{~V}$. These values are indicated as Voltage std. dev. $=0,0.4,0.8,1.4,1.6,2.0[\mathrm{~V}]$ in Fig. 18, which shows the plots obtained from six different simulations corresponding to the clean case (i.e. no noise injected, Voltage std. dev. $=0$ ) and five different noisy cases (i.e. distributions Voltage std. dev. $=0.4,0.8,1.4$, 1.6, $2.0[\mathrm{~V}]$ ). Essentially, input voltages have added to them random samples from the distributions corresponding to each of these standard deviations at each of the simulation steps. Again, the simulation is run for $2 \mathrm{~s}$ with time being represented on the $x$-axis, while the rotor speed is shown on the $y$-axis. The simulation is conducted for a speed step-up command to change the speed from 500 to 4000 RPM, similarly to the set-up from Fig. 14. This command is shown as Reference Speed in Fig. 18. It can be observed that the injected voltage noise starts affecting the motor operation at low speeds (i.e. 500 RPM) right away, once the noise standard deviation gets a value of $0.4 \mathrm{~V}$. As the noise standard deviation is increased towards $2 \mathrm{~V}$, the rotor speed ripples can reach up to 900 RPM, which is quite high. In contrast, at high rotor speeds (i.e. 4000 RPM), the impact of 
noise injection is smaller percentage-wise and the desired speed is tracked better. As the noise standard deviation is increased towards $2 \mathrm{~V}$, the rotor speed deviated down to $3700 \mathrm{RPM}$. Of note is that the authors also investigated the robustness of the hybrid controller against current measurement noise and found that the system was able to tolerate better such noise; that is, rotor speed was tracked better and ripples were smaller. The simulation plots are not reported here, but they can be found in [1].

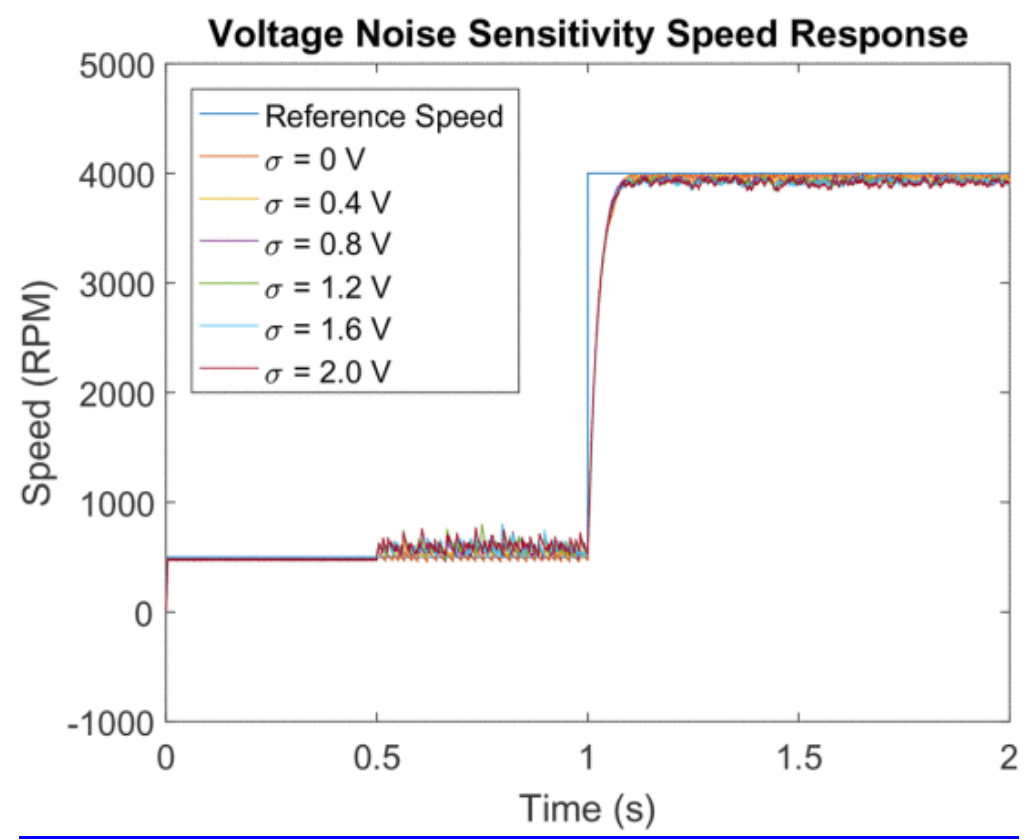

Fig. 18 Simulation results when noise is injected into voltage measurements

\subsubsection{Model parameter uncertainty}

In addition, simulations were conducted to study how the proposed controller can tolerate variations in the values of resistance and inductance in the motor model. While due to lack of space, the simulation plots are not reported here, it was found that the proposed hybrid controller becomes unstable as resistance is varied beyond -5 and $+10 \%$ around the nominal value. Also, the tolerable inductance ranges were from -5 to $+10 \%$ at high speeds and -5 to $+5 \%$ at low rotor speeds.

\section{SECTION 6 Hardware prototype of the proposed hybrid controller}

\subsection{Experimental setup}

A hardware prototype to test the operation of the proposed hybrid controller was developed. The motor used in experiments is the same Bull Running BR2804-1700 kV BLDC motor, which was modelled and used in the simulations from the previous section. The prototype is constructed with a Texas Instruments (TI) LAUNCHXLF28027 C2000 Piccolo Launchpad with the BOOSTXL-DRV8305EVM BoosterPack and a Teensy 3.2 development board.

The LAUNCHXL-F20827 features a TMS320F28027F Piccolo microcontroller, with a clock frequency of $60 \mathrm{MHz}$, $64 \mathrm{kB}$ of flash, and $12 \mathrm{kB}$ of RAM. It also includes 12-bit analogue-to-digital converter and 8-channel PWM peripherals. It is used to execute the algorithms that implement the proposed hybrid motor controller; that is, the FOC, DTC, and SMO techniques as well as their combination into the top-level hybrid scheme. The BOOSTXLDRM8305EVM includes the TI DRV8305 motor gate driver for three-phase BLDC motors. It provides short circuit, shoot-through, thermal, and under voltage protection. It is used as the main inverter that drives the Bull Running motor. In addition, it provides phase voltage and current values to the LAUNCHXL-F28027. The Teensy 
3.2 board features a 32-bit ARM processor overclocked at a clock frequency of $96 \mathrm{MHz}$. It is primarily used to play the role of a 'flight controller' whose task is to set desired rotor speeds for the LAUNCHXL-F28027F hybrid controller. It is also used to measure the motor's RPM. Of note, for numerical differentiation of some variable $x$, the standard approach based on $[x(k+1)-x(k)] / \Delta T$, is implemented; where $k$ is the sampling index (i.e. discrete time) and $\Delta T$ is the sampling time. Fig. 19 shows a picture of the entire experimental setup.

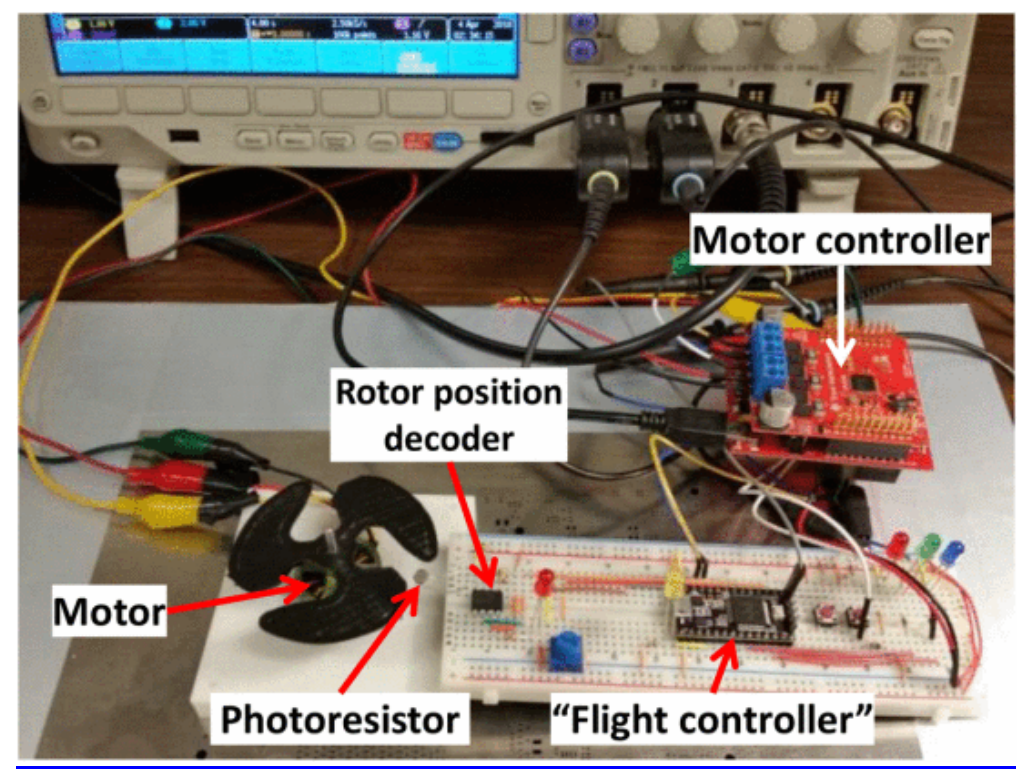

Fig. 19 Picture of the custom hardware setup to test the proposed hybrid controller

To calculate the rotor speed, a custom setup that uses a photoresistor to detect when a custom made blade crosses over is used. The photoresistor is part of a voltage divider circuit connected to an analogue comparator that is used then to generate a digital signal intercepting the moments in time of the blades crossing over the photoresistor. The 'flight controller' running on the Teensy 3.2 board is programmed to detect the falling edges of this comparator, which can be used to measure time of flight that in turn can be used to estimate the rotor speed and thus RPM with the following expression:

$$
\mathrm{RPM}=60 /(T \times N)
$$

where $T$ is the measured time between two adjacent blades passing over the photoresistor in seconds and $N=$ 3 is the number of blades. In addition, a digital-to-analogue converter is used to output a voltage proportional to the rotor speed, which is captured on an oscilloscope. Note that, alternatively one could estimate the rotor speed using information about the commutation times inside the motor controller implemented on the LAUNCHXL-F20827 Launchpad and have that communicated to the 'flight controller' running on the Teensy 3.2 board. This was not done in the current implementation. To start-up the motor, an open-loop control scheme is used until the motor is rotating fast enough.

\subsection{Testing results}

The testing consisted of a sequence of commands for desired speeds as follows: the desired rotor speed was set to 1000 RPM for the first $10 \mathrm{~s}$, then to 2500 RPM for the following $10 \mathrm{~s}$, and to 1500 RPM for a final $10 \mathrm{~s}$ period. Using a Tektronix MSO 3014 mixed signal oscilloscope, the following data were captured: the measured RPM expressed in $1 \mathrm{mV} / \mathrm{RPM}$ on the oscilloscope and a flag indicating whether the hybrid controller is running either the FOC or the DTC control technique. For each speed change command, the response time is measured from 
the time the rotor speed begins to change until it reaches $95 \%$ of the desired change. Fig. 20 shows the speed response of the proposed hybrid controller as measured by the oscilloscope. For clarity, the plot in Fig. 20 does not include the individual DTC and FOC curves; those curves look as shown in Fig. 14. During the initial startup, the rotor speed overshoots the desired speed, but eventually converges on the desired rotor speed of 1000 RPM. It can be seen that the rotor speed does experience some ripples, which are larger at high speeds than at low speeds. It is suspected, this may be due to the fact that the control loop in the hardware runs at $60 \mathrm{kHz}$ (limited by the microcontroller frequency and the actual complexity of the implementation) instead of $1 \mathrm{MHz}$ like in the case of simulations in Simulink/Matlab. There may also be some timing error on the Teensy board measurements which would cause larger errors at higher speeds. This potential hardware bug is under investigation. The response times for these speed changes were $<0.148 \mathrm{~s}$, as measured with the Tektronix MSO 3014 oscilloscope.

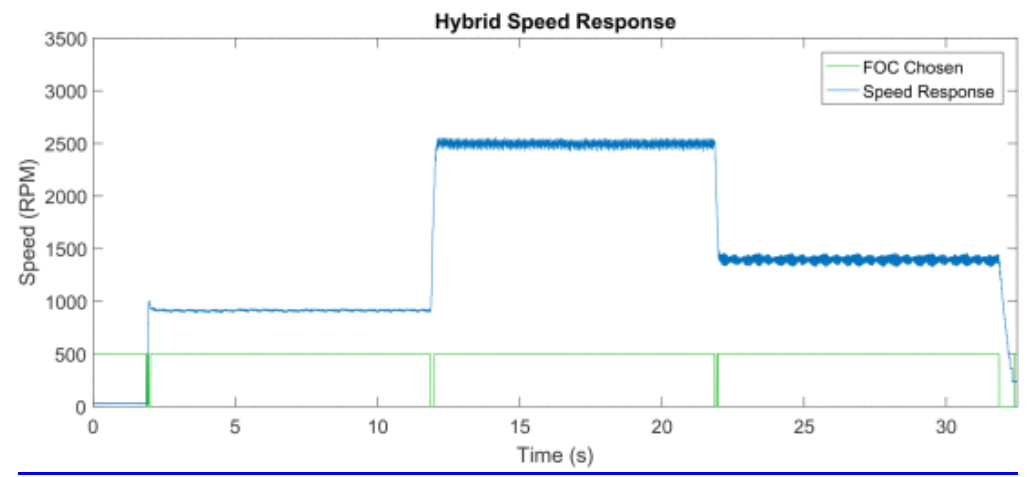

Fig. 20 Response of the proposed hybrid controller to commanded speed changes

Fig. 20 includes in the lower half of the plot also the flag signal recorded on the oscilloscope that indicates when the controller switched between the FOC and DTC techniques. This indicator is implemented by toggling one of the LaunchPad's GPIO pins high when the hybridisation module uses the FOC technique and low when the DTC technique is selected. In the figure, a value of 500 indicates the use of the FOC and a value of 0 indicates the use of DTC. As expected, the hybrid controller employed the DTC technique during startup and speed-change operations and switched to the FOC technique during steady-state operation.

The same hardware testing experiment was conducted for the hybrid controller and individually for the FOC and DTC techniques separately. Rather then presenting plots similar to those in Fig. 14 for the FOC and DTC techniques, the MSE of the rotor speed is calculated and reported to quantify differences between this technique and the proposed hybrid controller. The MSE of the rotor speed was calculated for each of the three experiments during a 10,000 point window where the rotor was operating during steady state. The results are reported in Table 5, where it can be seen that the hybrid controller achieved the lowest MSE overall. The average measured rotor speeds for each commanded desired speed are also included in Table 5. To find out the maximum attainable rotor speed by the hybrid controller, a desired speed of 20,000 RPM was commanded. It was found that the maximum speed attained by the Bull Running rotor was slightly over 3500 RPM.

Table 5 MSE results and achievable rotor speeds by the three different control techniques tested in hardware

\begin{tabular}{|l|l|l|l|l|}
\hline Control & MSE & $\begin{array}{l}\text { Achieved speed for desired } \\
\text { 1000 RPM }\end{array}$ & $\begin{array}{l}\text { Achieved speed for desired } \\
\text { 2500 RPM }\end{array}$ & $\begin{array}{l}\text { Achieved speed for desired } \\
\text { 1500 RPM }\end{array}$ \\
\hline DTC & 1.6165 & 899 RPM & 2366 RPM & 1365 RPM \\
\hline FOC & 0.6854 & 912 RPM & 2516 RPM & 1397 RPM \\
\hline hybrid & 0.6823 & 913 RPM & 2495 RPM & 1394 RPM \\
\hline
\end{tabular}




\section{SECTION 7 Conclusion}

In this paper, a hybrid control scheme for BLDC motors used in aerial drones was proposed. The proposed controller combines FOC and DTC techniques to take benefit of the advantages offered by each of these techniques individually. A complete derivation of the state-space equations that represent the electricalmechanical model of the BLDC motor was presented. This derived state-space model was then used in to investigate the performance of the proposed hybrid controller. Comprehensive simulation experiments demonstrated the effectiveness of the proposed control scheme over a wide range of rotor speeds. The performance of the proposed hybrid controller was verified also with a hardware prototype constructed to control a Bull Running motor, which is typically used in quadcopters. Experiments confirmed the results achieved via simulations for rotor speeds of up to 3500 RPM.

\section{ACKNOWLEDGMENTS}

This work was supported by the Department of Electrical and Computer Engineering at Marquette University and a Frank Rogers Bacon Research Assistantship.

\section{References}

1. K.D. Carey, "Hybrid sensorless field oriented and direct torque control for variable speed brushless DC motors", December 2017.

2. A. Stirban, I. Boldea, G.D. Andreescu et al., "Motion sensorless control of BLDC PM motor with ofline FEM info assisted state observer", Int. Conf. on Optimization of Electrical and Electronic Equipment, pp. 321-328, 2010.

3. C.L. Baratiei and H. Pinheiro, "An I-f starting method for smooth and fast transition to sensorless control of BLDC motors", Brazilian Power Electronics Conf., pp. 836-843, 2013.

4. T.H. Kim and M. Ehsani, "Sensorless control of the BLDC motors from near-zero to high speeds", IEEE Trans. Power Electron., vol. 19, no. 6, pp. 1635-1645, 2004.

5. T.S. Kim, B.G. Park, D.M. Lee et al., "A new approach to sensorless control method for brushless DC motors", Int. J. Control Autom. Syst., vol. 6, no. 4, pp. 477-487, 2008.

6. G.H. Jang, J.H. Park and J.H. Chang, "Position detection and start-up algorithm of a rotor in a sensorless BLDC motor utilizing inductance variation", Electr. Power Appl. Proce., vol. 149, no. 2, pp. 137, 2002.

7. C.G. Kim, J.H. Lee, H.W. Kim et al., "Study on maximum torque generation for sensorless controlled brushless DC motor with trapezoidal back EMF", Electr. Power Appl. Proc., vol. 152, no. 2, pp. 277, 2005.

8. R. Gabriel, W. Leonhard and C.J. Nordby, "Field-oriented control of a standard AC motor using microprocessors", IEEE Trans. Ind. Appl., vol. IA-16, no. 2, pp. 168-192, 1980.

9. P. Tiitinen, P. Pohjalainen and J. Lalu, "The next generation of motor control method: direct torque control (DTC)", EPE J., vol. 5, no. 1, pp. 14-18, 1995.

10. J.C. Gamazo-Real, E. Vazquez-Sanchez and J. Gomez-Gil, "Position and speed control of brushless DC motors using sensorless techniques and application trends", Sensors, vol. 10, pp. 6901-6947, 2010.

11. X. Zhou, Y. Zhou, C. Peng et al., "Sensorless BLDC motor commutation point detection and phase deviation correction method", IEEE Trans. Power Electron., 2018.

12. T. Li and J. Zhou, "High-stability position-sensorless control method for brushless DC motors at low speed", IEEE Trans. Power Electron., 2018.

13. S. Bouabdallah, "Design and control of quadrotors with application to autonomous flying", 2006.

14. M. Orsag, C. Korpela, S. Bogdan et al., "Dexterous aerial robots-mobile manipulation using unmanned aerial systems", IEEE Trans. Robot., vol. 33, no. 6, pp. 1453-1466, 2017.

15. W. Giernacki, "Near to optimal design of PIXD $\mu$ fractional-order speed controller (FOPID) for multirotor motor-rotor simplified model", Int. Conf. on Unmanned Aircraft Systems (ICUAS), pp. 320-326, 2016. 
16. A. Franchi and A. Mallet, "Adaptive closed-loop speed control of BLDC motors with applications to multirotor aerial vehicles", IEEE Int. Conf. on Robotics \& Automation, 2017.

17. UAV BLDC Motor Controller ESC with Field Oriented Control (FOC) and CAN, NXP Solutions, 2018. https://www.nxp.com/applications/solutions/internet-of-things/smart-things/unmanned-aerialvehicles-uavs/motorcontrols-and-actuators/uav-bldc-motor-controller-esc-with-field-orientedcontrolfoc-and-can:UAV-BLDC-MOTOR-CONTROLLER-FOC

18. Sensorless High-Speed FOC Reference Design for Drone ESC, Texas Instruments Designs, 2018. http://www.ti.com/tool/TIDA-00916

19. Electronic speed controller reference design for drones, ST Reference Design, 2018. https://www.st.com/content/st_com/en/products/evaluation-tools/ solution-evaluation-tools/motorcontrol-solution-eval-boards/stevalesc001v1.html

20. P.K. Girija and A. Prince, "Robustness evaluation of SMO in sensorless control of BLDC motor under DTC scheme", Int. Conf. on Power Signals Control and Computations, 2014.

21. A. Deenadayalan and G.S. llango, "Modified sliding mode observer for position and speed estimations in brushless DC motor", IEEE India Conf., 2011.

22. H. Zhang, Y. Tu and T. Wang, "Sensor-less control for brushless DC motors based on hybrid sliding mode observer", Int. Conf. on Intelligent Computation Technology and Automation, pp. 636-640, 2014.

23. H. Fakham, M. Djema and K. Busawon, "Design and practical implementation of a back-emf sliding mode observer for brushless DC motor", IET Power Appl., vol. 2, no. 6, pp. 353-361, 2008.

24. A. Deenadayalan and G.S. Ilango, "Position sensorless sliding mode observer with sigmoid function for brushless DC motor", Int. Conf. on Advances in Power Conservation and Energy Technologies, 2012.

25. L. Hao and H. Toliyat, "BLDC motor full-speed operation using hybrid sliding mode observer", IEEE Applied Power Electronics Conf. and Exposition, pp. 286-293, 2003.

26. W. Yan, H. Lin, M. Wang et al., "Variable structure sliding mode based unknown input observer for speed identification of brushless DC motors", IEEE Int. Conf. on Robotics and Biomimetrics, pp. 2188-2193, 2009.

27. M.R. Feyzi, M. Shafiei, M.B. Kouhshahi et al., "Position sensorless direct torque control of brushless dc motor drives based on sliding mode observer using NSGA-II algorithm optimization", Power Electronics Drive Systems and Technologies Conf., pp. 151-156, 2011.

28. Z. Peixoto, F. Sa, P. Seixas et al., "Speed control of permanent magnet motors using sliding mode observers for induced EMF position and speed estimation", IEEE Conf. on Industrial Electronics, pp. 1023-1028, 1995.

29. T. Chang, W. Wang, Y. Wong et al., "Sensorless permanent-magnet synchronous motor drive using a reduced-order rotor flux observer", IET Electr. Power Appl., vol. 2, no. 2, pp. 88-98, 2008.

30. L. Prokop and L. Chalupa, "3-Phase BLDC Motor Control with sensorless back emf zero crossing detection using 56F80x", 2005.

31. Renesas, Motor control by RL78/G14 micro controller sensorless 120 degrees conducting control of brushless DC motor, Application Note R01AN1389EJ0100, 2012

32. M.S. Tiersten, "Moments not to forget - the conditions for equating torque and rate of change of angular momentum around the instantaneous center", Am. J. Phys., vol. 59, no. 8, pp. 733-738, 1991.

33. P. Pillay and R. Krishnan, "Modeling simulation and analysis of permanent-magnet motor drives part II: the brushless DC motor drive", IEEE Trans. Ind. Appl., vol. 25, no. 2, pp. 275-279, 1989.

34. M. Yano, S. Abe and E. Ohno, "History of power electronics for motor drives in Japan", IEEE Conf. on the History of Electronics, 2004.

35. G.K. Dubey, Fundamentals of electrical drives, Boca Raton, FL, USA:CRC Press, 2002.

36. Microsemi, Park, Inverse Park and Clarke, Inverse Clarke Transformations MSS Software Implementation, Application Note 
37. T. Noguchi and I. Takahashi, "Quick torque response control of an induction motor based on a new concept", IEEJ Tech. Meeting Rotating Mach., pp. 61-70, 1984.

38. I. Takahashi and T. Noguchi, "A new quick-response and high-efficiency control strategy of an induction motor", IEEE Trans. Ind. Appl., vol. 22, no. 5, pp. 820-827, 1986.

39. M.S. Merzoug and F. Naceri, "Comparison of field-oriented control and direct torque control for permanent magnet synchronous motor (PMSM)", World. Acad. Sci. Eng. Technol., vol. 35, pp. 299-304, 2008.

40. G.R.A. Markadeh, S.I. Mousavi, S. Abazari et al., "Position sensorless direct torque control of BLDC motor", Optim. Electr. Electron. Equip., 2008.

41. J.B. Brandt, R.W. Deters, G.K. Ananda et al., "UIUC propeller database", 2008. 